\title{
Household Debt, Financial Intermediation, and Monetary Policy
}

\author{
Yahong Zhang (University of Windsor)
}

Working paper $15-04$

Working papers are in draft form. This working paper is distributed for purposes of comment and discussion only. It may not be reproduced without permission of the copyright holder. Copies of working papers are available from the author or at http://ideas.repec.org/s/wis/wpaper.html. 


\title{
Household Debt, Financial Intermediation, and Monetary Policy
}

\author{
Yahong Zhang *
}

November 11, 2015

\begin{abstract}
The collapse of the housing prices in the U.S. during the Great Recession not only eroded housing wealth held by households, but also the values of the assets in the banking sector. As a result, during the Great Recession mortgage risk premium increases significantly. I introduce a micro-founded banking sector to a standard DSGE model with household debt to study the interaction between housing prices, household debt and banks' balance sheet positions. I estimate the model using the US data from 1991Q1 to 2014Q1. I find that the model accounts well the negative relationship between housing prices and mortgage risk premium. In the model, a weakened households' demand for housing leads to a decline in housing prices, which worsens the banks' balance sheet positions, and as a result, risk premium rises. The results show that housing demand shocks as well as shocks that increases the riskiness of the banking sector contribute significantly to the decline in output during the Great Recession. I also find that the unconventional monetary policy implemented by the Federal Reserve mitigates the decline in output.
\end{abstract}

JEL: classification: E32;E44; E52

Keywords: household debt, risk premium, banking, unconventional monetary policy

*Department of Economics, University of Windsor, Windsor, Ontario, Canada N9B 3P4; E-mail: yzhang@uwindsor.ca. This project was initially developed with Shutao Cao. I am grateful for Shutao's many valuable comments and suggestions as well as his help with the data. I also thank Jim MacGee, Nurlan Turdaliev, Marcelo Arbex, the seminar participants at the University of Western Ontario, and the University of Windsor, as well as the participants at the 2015 Canadian Economics Association Annual Meeting for helpful comments and discussions. All remaining errors are my own. 


\section{Introduction}

The collapse of the housing prices in the U.S. during the Great Recession not only eroded housing wealth held by households, but also the values of the assets in the banking sector. The deterioration of banks' balance sheet condition resulted in a rise in risk premium in both business loan and mortgage loan. Figure 1 illustrates the movements in both house price and mortgage risk premium for the U.S. from 1991Q1 to 2014Q1. What was the most striking is the steep decline in housing prices and sharp rise in risk premium during the Great Recession (the second shaded area). On the real side of the economy, the rise in risk premium has led to a decline in borrowing for both households and firms, leading declines in both business and housing investments. On the policy front, the deterioration of banks' balance sheet and the rise in the mortgage spread were the key factors that triggered the Federal Reserve to intervene heavily in mortgage markets by directly purchasing mortgage-backed securities from the banking sector.

Figure 1: House Prices and Mortgage Risk Premium 1991Q1-2014Q1

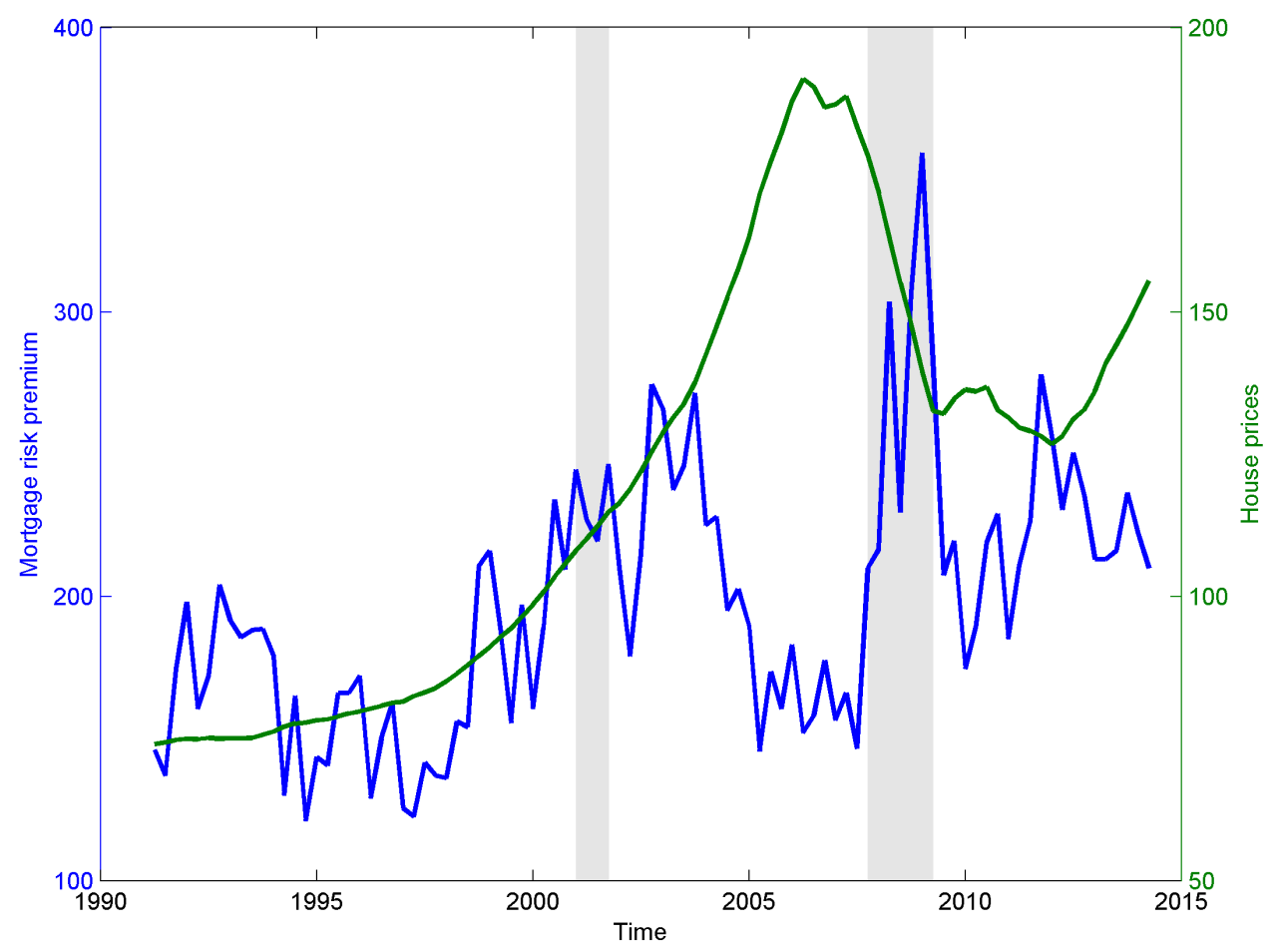

Mortgage risk premium is in basis points and constructed using 30 year fixed rate mortgage loan minus the average of 10 year government debt yield and 5 year government debt yield. Housing prices are S\&P/Case-Shiller Home Price Indices.

Banking sector, however, is largely absent in the existing works in the DSGE models studying housing wealth and consumption. ${ }^{1}$ Due to this, the existing models are not only incapable of ad-

\footnotetext{
${ }^{1}$ [Iacoviello, 2005], built upon [Kiyotaki and Moore, 1997], is the seminal work in this branch of literature. For
} 
dressing the interactions between households' and banks' balance sheets, but also the impact of the unconventional monetary policy on household debt and the aggregate economy. To my knowledge, the only exception is [Iacoviello, 2015], which introduces a simple banking sector to an otherwise standard DSGE model with household debt. In his model, the limitation of raising deposits from households for banks generates a wedge between the deposit rate and lending rate. The drawback of the paper is that there is no micro-foundation for why banks face this limitation. In addition, [Iacoviello, 2015] is a purely real model, and thus monetary policy is absent in the model.

Thus, the goal of this paper is to propose a model that allows us to study the interaction between housing prices, households' debt, and banks' balance sheet positions, and to assess quantitatively the impact of the unconventional monetary policy on household debt and the aggregate economy. To achieve this, I introduce a banking sector that is similar to [Gertler and Karadi, 2011] and [Gertler and Kiyotaki, 2015] to a DSGE model with household debt. In the model, there are two principal-agent problems: one is between borrowers and banks, and the other one is between depositors and banks. On one hand, the default risks and the enforcement problem between borrowers and banks lead to a standard collateral requirement for borrowers. On the other hand, the frictions in the principal-agent relationship between the banks and depositors generate a spread between the lending rate and the rate that banks pay to their depositors. In particular, it is assumed that there is a moral hazard problem between the banks and depositors: the banks can divert a fraction of the funds supplied by the depositors at the end of each period, at the costs that the relationship with depositors will be terminated. In the model, the banks' capacity of raising deposits is limited due to the concerns of the depositors that part of their funds can be diverted. Risk premium is a natural outcome due to this limitation since otherwise the arbitrage condition will drive the gap between lending rate and borrowing rate to zero. This limitation of raising deposits constraint tightens if banks are more likely to divert funds or they become less capitalized.

The key mechanism at work is as follows: the banks intermediate funds between depositors and borrowers, including the borrowers from both household sector and business sector. To be specific, the banks buy claims issued by households and firms. A bank's net worth varies with the price of the claims. When there is a negative shock to the housing demand, house prices drop, resulting a decline in housing wealth held by households. Since housing wealth is used as collateral for the households to obtain mortgage loans, the demand for household debt declines, and this drives down the prices of the claims which the banks hold. As a result, banks' net worth declines and the constraint on the raising deposit tightens. The tightening of the banks' ability of raising deposits leads to a rise in risk premium. This is the mechanism in the paper that allows us to capture the negative correlation between housing prices and risk premium in the data.

In order to make the model more suitable for delivering quantitative results, the baseline framework in this paper is the conventional monetary business cycle framework as in [Christiano et al., 2005]

examples of estimating this type of model, see [Neri and Iacoviello, 2010]. For recent examples of applying this type of model to study household debt, see [Justiniano et al., 2015]. 
and [Smets and Wouters, 2007], including features such as habit persistence, investment adjustment costs and nominal rigidity. I use the Bayesian method to estimate the model using the U.S. data from 1991Q1 to 2014Q1. The main findings are as follows: first, I find that the financial frictions faced by the banks give rise to a "banking financial accelerator" mechanism which is similar to what is described in [Bernanke et al., 1999]: For the shocks that increase the prices of the assets held by the banks, the financial frictions amplifies the impact of the shocks. ${ }^{2}$ For instance, an expansionary monetary policy shock increases the prices of the assets held by the banks, and in turn, increases the net worth of the banks and improves the banks' balance sheet positions. This results in a lower risk premium, which leads both firms and households to borrow more, and further increases the prices of the assets held by the banks. Second, I find that the housing demand shocks and banking sector shocks contribute about half of the decline in output during the Great Depression. The sharp rise in risk premium during the Great Recession was almost entirely due to the banking sector shocks. Lastly, I conduct experiments to examine the effects of the unconventional monetary policy. I find that injecting equity to the banking sector moderates the downturn, particularly when the economy is buffeted by banking sector shocks.

The remaining of the paper is organized as follows. In Section 2, I describe the model. Section 3 contains data and estimation. I analyze the model's performance in Section 4 and conduct experiments on the unconventionary monetary policy in Section 5. I offer some concluding remarks in Section 6.

\section{The Model}

Consider a discrete time, infinite horizon economy, populated by five types of agents: households, house producers, goods producers, a government and financial intermediaries. Their optimization problems and the market clearing conditions are as follows:

\subsection{Households}

Households are infinitely lived and measure 1. There are two types of households, patient and impatient, which differ only by the rate at which they discount the future. Patient households are denoted by $p$, and represent a share of $\alpha$ of the population. Impatient households are denoted by $i p$, and represent a share of $1-\alpha$ of the population. The discount factors for the patient and impatient households are $\beta_{p}$ and $\beta_{i p}$ respectively, with $\beta_{p}>\beta_{i p}$. In the model, because the impatient households discount the future more, they are the borrowers, and the patient households are the lenders. The financial intermediaries channel the funds from lenders to borrowers.

\subsubsection{Patient households' problem}

$$
E_{0} \sum_{t=0}^{\infty} \beta_{p}^{t}\left(\varepsilon_{t}^{c} \log \left(c_{p, t}-b c_{p, t-1}\right)+\varepsilon_{t}^{h} \phi \log h_{p, t}-\psi \frac{n_{p, t}^{1+\eta}}{1+\eta}\right),
$$

\footnotetext{
${ }^{2}$ In [Bernanke et al., 1999], it is the firms who face financial frictions.
} 
where $c_{p, t}$ denotes consumption of non-durable goods for the patient households, $h_{p, t}$ is the stock of houses at the end of period $t$, and $n_{p, t}$ is hours worked. $\varepsilon_{t}^{c}$ is a consumption demand shock that obeys

$$
\log \varepsilon_{t}^{c}=\rho^{c} \log \varepsilon_{t-1}^{c}+\zeta_{t}^{c},
$$

and $\varepsilon_{t}^{h}$ is a housing demand shock that follows

$$
\log \varepsilon_{t}^{h}=\rho^{h} \log \varepsilon_{t-1}^{h}+\zeta_{t}^{h},
$$

both $\zeta_{t}^{c}$ and $\zeta_{t}^{h}$ are zero-mean i.i.d. random variables. All variables are in per-capita real terms. The stock of houses evolves according to

$$
h_{p, t}=\left(1-\delta_{h}\right) h_{p, t-1}+i_{p, t}^{h},
$$

where $i_{p, t}^{h}$ is residential investment (i.e. new houses) and $\delta_{h}$ is the rate of depreciation of the housing stocks. The household faces the following budget constraint

$$
P_{t} c_{p, t}+P_{t}^{h} i_{p, t}^{h}+D_{t}<=W_{p, t} n_{p, t}+R_{t-1} D_{t-1}-T_{t}+\Pi_{t}
$$

where $P_{t}$ and $P_{t}^{h}$ are the prices of the consumption good and of houses, while $R_{t}$ and $W_{p, t}$ are the nominal interest rate and wage rate. $D_{t}$ is the amount of deposits by the end of period $t$, and carried into period $t+1$. Following [Iacoviello, 2005], it is assumed that it is the patient households (not the impatient households) who pay tax $T_{t}$, and receive $\Pi_{t}$, which includes the profits from the retailers, plus the value of the assets received from the exiting bankers, minus the transfer to the newly entered bankers. ${ }^{3}$ In real terms, the budget constraint is:

$$
c_{p, t}+q_{t} i_{p, t}^{h}+d_{t}<=w_{p, t} n_{p, t}+R_{t-1}^{d} \frac{d_{t-1}}{\pi_{t}}-t_{t}+\pi_{t}
$$

where $q_{t}=\frac{P_{t}^{h}}{P_{t}}$.

Households maximize their life-time utility (1) subject to equations (2) and (4) by choosing $c_{p, t}, d_{t}, n_{p, t}, i_{p, t}$ and $h_{p, t}$. Let $\lambda_{1, t}^{p}$ and $\lambda_{2, t}^{p}$ be the Lagrangian multipliers associated with equations (2) and (4). The first-order conditions are:

$c_{p, t}$ :

$$
\varepsilon_{t}^{c} \frac{1}{c_{p, t}-b c_{p, t-1}}-\beta_{p} b \varepsilon_{t+1}^{c} \frac{1}{c_{p, t+1}-b c_{p, t}}-\lambda_{1, t}^{p}=0
$$

$d_{t}:$

$$
\lambda_{1, t}^{p}=E_{t} \beta_{p} R_{t} \frac{\lambda_{1, t+1}^{p}}{\pi_{t+1}},
$$

$n_{p, t}:$

$$
\varphi n_{p, t}^{\eta}=\lambda_{1, t}^{p} w_{p, t}
$$

\footnotetext{
${ }^{3}$ Given the lump-sum nature, the optimal allocations are not affected by who pay tax and receive retaining earnings.
} 
$i_{p, t}:$

$$
\lambda_{1, t}^{p} q_{t}=\lambda_{2, t}^{p}
$$

and $h_{p, t}$ :

$$
\frac{\varepsilon_{t}^{h} \phi}{h_{p, t}}-\lambda_{2, t}^{p}+E_{t} \beta_{p} \lambda_{2, t+1}^{p}(1-\delta)=0,
$$

Equations (5) and (6) characterize the standard Euler equation for consumption goods with the presence of habit formation:

$$
\varepsilon_{t}^{c} \frac{1}{c_{p, t}-b c_{p, t-1}}-\beta_{p} b \varepsilon_{t+1}^{c} \frac{1}{c_{p, t+1}-b c_{p, t}}=E_{t} \beta_{p} R_{t} \frac{\varepsilon_{t+1}^{c} \frac{1}{c_{p, t+1}-b c_{p, t}}-\beta_{p} b \varepsilon_{t+2}^{c} \frac{1}{c_{p, t+2}-b c_{p, t+1}}}{\pi_{t+1}} .
$$

Equations (8) and (9) give us the Euler equation for housing:

$$
\frac{\varepsilon_{t}^{h} \phi}{h_{p, t}}+\beta_{p} E_{t} \lambda_{1, t+1}^{p} q_{t+1}\left(1-\delta_{h}\right)=q_{t} \lambda_{1, t}^{p} .
$$

This intertemporal condition for housing requires the borrowers to equate the marginal utility of current consumption $q_{t} \lambda_{1, t}^{p}$ to the marginal gain of housing, which consists of two terms: the direct utility gain of an additional unit of housing $\frac{\varepsilon_{t}^{h} \phi}{h_{p, t}}$, and the expected gain in terms of future consumption by selling the housing asset (discounted by depreciation) $\beta_{p} E_{t} \lambda_{1, t+1}^{p} q_{t+1}\left(1-\delta_{h}\right)$. Equation (7) governs the household's decision on consumption and leisure choices.

\subsubsection{Impatient households' problem}

The impatient households' problem is similar to the one faced by the patient households except that they are also subject to a borrowing constraint. The impatient households maximize their lifetime utility

$$
E_{0} \sum_{t=0}^{\infty} \beta_{i p}^{t}\left(\varepsilon_{t}^{c} \log \left(c_{i p, t}-b c_{i p, t-1}\right)+\varepsilon_{t}^{h} \phi \log h_{i p, t}-\psi \frac{n_{i p, t}^{1+\eta}}{1+\eta}\right),
$$

subject to a housing accumulation equation

$$
h_{i p, t}=\left(1-\delta^{h}\right) h_{i p, t-1}+i_{i p, t}^{h},
$$

and a budget constraint

$$
P_{t} c_{i p, t}+P_{t}^{h} i_{i p, t}^{h}+R_{t-1}^{l} L_{t-1} \leq W_{i p, t} n_{i, t}+L_{t}
$$

where $L_{t}$ denotes the amount of loan that the impatient households borrow from the financial intermediaries. Note that the borrowing rate $R_{t-1}^{l}$ is different from the deposit rate $R_{t-1}$. The existence of risk premium will be explained in the following financial intermediary section. In real terms, 
equation (14) is

$$
c_{i p, t}+q_{t} i_{i p, t}^{h}+R_{t-1}^{l} \frac{l_{t-1}}{\pi_{t}}<=w_{i p, t} n_{i p, t}+l_{t} .
$$

Following [Iacoviello, 2015], I assume that the impatient households are subject to the following borrowing constraint

$$
L_{t}<=\rho^{l} L_{t-1}+\left(1-\rho^{l}\right) \frac{E_{t} \varepsilon_{t}^{\theta} \theta P_{t+1}^{h} h_{i p, t}\left(1-\delta_{h}\right)}{R_{t}^{l}} .
$$

Allowing $\rho^{l}>0$ captures the idea that in each quarter, only a fraction of the mortgage loans is either newly issued or renegotiated. In the U.S. for mortgage loans, the most common terms are 15 and 30 year fixed rate loans. Equation (16) can be thought of as a reduced way to deal with long-term debt in a model estimated at quarterly frequency. In other words, $\rho^{l}$ can be thought of as the persistence of the mortgage loan. When $\rho^{l}=0$, equation (16) is reduced to the standard collateral constraint

$$
L_{t}<=\frac{E_{t} \varepsilon_{t}^{\theta} \theta P_{t+1}^{h} h_{i p, t}\left(1-\delta_{h}\right)}{R_{t}^{l}},
$$

that is, the maximum amount that the impatient households can borrow is a fraction $\varepsilon_{t}^{\theta} \theta$ of their housing wealth $P_{t+1}^{h} h_{i p, t}\left(1-\delta_{h}\right)$, where $\varepsilon_{t}^{\theta}$ is a shock to the loan-to-value ratio $\theta$, which follows

$$
\log \varepsilon_{t}^{\theta}=\rho^{\theta} \log \varepsilon_{t-1}^{\theta}+\zeta_{t}^{\theta}
$$

The borrowing constraint (16) in real terms is

$$
l_{t}<=\rho^{l} l_{t-1}+\left(1-\rho^{l}\right) \frac{E_{t} \varepsilon_{t}^{\theta} \theta q_{t+1} \pi_{t+1} h_{i p, t}\left(1-\delta_{h}\right)}{R_{t}^{l}} .
$$

The impatient households maximize their life-time utility (12) subject to equations (13), (15) and (18) by choosing $c_{i p, t}, l_{t}, n_{i p, t}, i_{i p, t}$ and $h_{i p, t}$. Let $\lambda_{1, t}^{i p}, \lambda_{2, t}^{i p}$ and $\lambda_{3, t}^{i p}$ be the Lagrangian multipliers associated with equations (13), (15) and (18). The first-order conditions are:

$c_{i p, t}:$

$$
\varepsilon_{t}^{c} \frac{1}{c_{i p, t}-b c_{i p, t-1}}-\beta_{p} b \varepsilon_{t+1}^{c} \frac{1}{c_{i p, t+1}-b c_{i p, t}}-\lambda_{1, t}^{i p}=0
$$

$l_{i p, t}:$

$$
\lambda_{1, t}^{i p}=E_{t} \beta_{i p} R_{t}^{l} \frac{\lambda_{1, t+1}^{i p}}{\pi_{t+1}}+\lambda_{3, t}^{i p} R_{t}^{l}-E_{t} \beta_{i p} \lambda_{3, t+1}^{i p} R_{t+1}^{l} \rho^{l}
$$

$n_{i p, t}:$

$$
\varphi n_{i p, t}^{\eta}=\lambda_{1, t}^{i p} w_{i p, t},
$$

$i_{i p, t}^{h}:$

$$
\lambda_{1, t}^{i p} q_{t}=\lambda_{2, t}^{i p},
$$


$h_{i p, t}:$

$$
\varepsilon_{t}^{h} \frac{\phi}{h_{i p, t}}-\lambda_{2, t}^{i p}+E_{t} \lambda_{2, t+1}^{i p} \beta_{i p}\left(1-\delta_{h}\right)+\left(1-\rho^{l}\right) \lambda_{3, t}^{i p} E_{t} \theta \varepsilon_{t}^{\theta} q_{t+1} \pi_{t+1}\left(1-\delta_{h}\right)=0 .
$$

Equation (20) and (19) gives us the consumption Euler equation for the impatient households

$$
\lambda_{1, t}^{i p}=E_{t} \beta_{i p} R_{t}^{l} \frac{\lambda_{1, t+1}^{i p}}{\pi_{t+1}}+\lambda_{3, t}^{i p} R_{t}^{l}-E_{t} \beta_{i p} \lambda_{3, t+1}^{i p} R_{t+1}^{l} \rho^{l} .
$$

The Euler equation for housing can be derived by equations (22) and (23):

$$
\varepsilon_{t}^{c} \varepsilon_{t}^{h} \frac{\phi}{h_{i p, t}}+E_{t}\left\{\beta_{i p} \lambda_{1, t+1}^{i p} q_{t+1}\left(1-\delta_{h}\right)+\left(1-\rho^{l}\right) \lambda_{3, t}^{i p} \theta \varepsilon_{t}^{\theta} q_{t+1} \pi_{t+1}\left(1-\delta_{h}\right)\right\}=\lambda_{1, t}^{i p} q_{t}
$$

Compared to the first order conditions for consumption and housing for the patient households, there are additional terms which are related to the borrowing constraint for the impatient households. To get some intuitions for why these terms appear in equations (24) and (25), without loss of generality let us assume that $\rho^{l}=0$. With $\rho^{l}=0$,equations (24) and (25) are reduced to

$$
\lambda_{1, t}^{i p}=E_{t} \beta_{i p} R_{t}^{l} \frac{\lambda_{1, t+1}^{i p}}{\pi_{t+1}}+\lambda_{3, t}^{i p} R_{t}^{l},
$$

and

$$
\varepsilon_{t}^{c} \varepsilon_{t}^{h} \frac{\phi}{h_{i p, t}}+E_{t}\left\{\beta_{i p} \lambda_{1, t+1}^{i p} q_{t+1}\left(1-\delta_{h}\right)+\lambda_{3, t}^{i p} \theta \varepsilon_{t}^{\theta} q_{t+1} \pi_{t+1}\left(1-\delta_{h}\right)\right\}=\lambda_{1, t}^{i p} q_{t} .
$$

The Euler equation for consumption equation (26) for the impatient household indicates that when the borrowing constraint is binding $\lambda_{3, t}^{i p}>0$, the marginal gain of consuming today $\lambda_{1, t}^{i p}$ exceeds the marginal utility of consuming tomorrow $E_{t} \beta_{i p} R_{t}^{l} \frac{\lambda_{1, t+1}^{i p}}{\pi_{t+1}}$. The larger $\lambda_{3, t}^{i p}$ is, the tighter the borrowing constraint is, and therefore the larger the difference between consuming in the current period with in the future. For the Euler equation for housing consumption equation (27), the rise in $\lambda_{3, t}^{i p}$ will lead to a higher marginal gain of acquiring an additional unit of housing $\lambda_{1, t}^{i p} q_{t}$. This is because a tighter borrowing constraint (that is, a higher marginal gain of relaxing the constraint) will lead to a higher marginal gain of acquiring an additional unit of housing (housing can be used as collateral to relax the borrowing constraint).

\subsection{Financial intermediaries}

In the beginning of the period $t$, the net worth for each financial intermediary (bank) is $n_{t}$. The bank will fund capital producers' capital investment $k_{t}$ and lend mortgage loans $l_{t}$ to the impatient households by issuing deposits $d_{t}$ to the patient households, as well as using their own net worth $n_{t}$. 
We can think of the total assets $A_{t}$ as the total financial claims the bank buys, thus at the beginning of the period $t$, the total assets for the bank are

$$
A_{t}=Q_{t} S_{t}
$$

where $S_{t}=k_{t}+l_{t}$, and $Q_{t}$ is the price of the claims. The flow of funds equation thus is

$$
A_{t}=Q_{t}\left(k_{t}+l_{t}\right)=d_{t}+n_{t}
$$

Let $R_{t+1}^{l}$ be the realized return on the financial claims at the end of period $t$ (or at the beginning of period $t+1$ ), and $R_{t+1}$ is the return on the deposits at the end of period $t$. At the end of the period $t$, the bank's net worth $n_{t+1}$ is the gross payoff from assets that the bank funded at the beginning of the period, minus borrowing costs

$$
n_{t+1}=R_{t+1}^{l} Q_{t} S_{t}-R_{t+1} d_{t}=R_{t+1}^{l} Q_{t}\left(k_{t}+l_{t}\right)-R_{t+1} d_{t}
$$

which can be further expressed as

$$
n_{t+1}=\left(R_{t+1}^{l}-R_{t+1}\right) Q_{t}\left(k_{t}+l_{t}\right)+R_{t+1} n_{t}
$$

Let $s_{t}$ denote the risk premium - the difference between the lending rate $R_{t}^{l}$ and borrowing rate $R_{t}$. The existence of the risk premium is due to the fact that the bank faces a limitation of raising deposits from the patient households. If there is no limitation of raising deposits, the interest rate spread will disappear eventually: the increase in the deposits will require a rise in the deposit rate $R_{t+1}$ and the rise in bank's assets will generally leads to a decline in $R_{t+1}^{l}$, the rate of return on these assets.

In order to motivate the limitation of raising deposits, I follow [Gertler and Karadi, 2011] and [Gertler and Kiyotaki, 2015], to introduce a moral hazard problem to the banking sector: at the end of the each period $t$ the bank can choose to divert the fraction of $\kappa$ of assets for personal use. The cost is that the bank can be forced into bankruptcy at the beginning of the next period. In this environment, for the patient households to be willing to lend to the bank, the following incentive constraint must be satisfied:

$$
\varepsilon_{t}^{\kappa} \kappa Q_{t} S_{t} \leq V_{t}
$$

that is, the present value of payout from operating the bank, $V_{t}$, must exceed the gain of diverting assets. $\varepsilon_{t}^{\kappa}$ is a shock to the fraction of assets that can be diverted. In equilibrium, diverting funds never happens. The diverting funds shocks, however, can be thought of as an indicator for the vulnerability of the banking sector. During the financial crisis, there was an increased difficulties for banks to obtain funds from depositors since depositors have less confidence in banks' ability of allocating funds properly and efficiently. We can think of diverting funds shock as a sudden rise in 
riskiness in the banking sector. It follows

$$
\log \varepsilon_{t}^{\kappa}=\rho^{\kappa} \log \varepsilon_{t-1}^{\kappa}+\zeta_{t}^{\kappa}
$$

There is a threshold level of deposits such as if the deposits received by the bank exceed the threshold, the bank would have the incentive to default. Given this, the patient households will choose not to expand their deposits beyond the threshold and as a result there is interest rate spread between lending and borrowing rates in the model.

Given the financial frictions, the banks have the incentive to accumulate retained earnings in order to eventually only use his internal funds. To limit this possibility, I assume that the banks have finite expected lifetime. In each period, the banks are subject to an i.i.d probability $\sigma$ of surviving, and a probability of $1-\sigma$ of exiting. It is assumed that the banks pay dividends only when they exit. ${ }^{4}$ Thus the objective of the banks is to maximize the expected present value of future dividends

$$
V_{t}=E_{t} \sum_{i=1}^{\infty}\left[\left(\beta^{p}\right)^{i} \Lambda_{t, t+i}(1-\sigma) \sigma^{i-1} n_{t+i}\right],
$$

where $\Lambda_{t, t+1}=c_{p, t} / c_{p, t+1}$. This can be expressed recursively as

$$
V_{t}=E_{t}\left[\beta^{p} \Lambda_{t, t+1}(1-\sigma) n_{t+1}+\beta^{p} \Lambda_{t, t+1} \sigma V_{t+1}\right]
$$

The banks' problem thus is: given $Q_{t}$, the bank maximizes equation (31) by choosing $d_{t}$ and $S_{t}$, subject to the incentive constraint (30) and the flow of funds constraints (28) and law of motion for net worth (29).

Given that both the objective and constraints of the banks are constant returns to scale, let $\varphi_{t}=$ $V_{t} / n_{t}$, and let $\phi_{t}=\frac{Q_{t} S_{t}}{n_{t}}$. It can be shown that: ${ }^{5}$

$$
\varphi_{t}=\max \mu_{t} \phi_{t}+v_{t}
$$

where,

$$
\begin{gathered}
\mu_{t}=\beta^{p} \Lambda_{t, t+1} E_{t}\left[\left(R_{t+1}^{l}-R_{t+1}\right) \Omega_{t+1}\right], \\
v_{t}=\beta^{p} \Lambda_{t, t+1} E_{t}\left[R_{t+1} \Omega_{t+1}\right]
\end{gathered}
$$

and

$$
\Omega_{t+1}=1-\sigma+\sigma \varphi_{t+1} .
$$

$\mu_{t}$ can be thought as the excess marginal value of assets over deposits since it depends on $\left(R_{t+1}^{l}-\right.$ $R_{t+1}$ ), the excess return per unit of assets the banker intermediates. $v_{t}$ depends on $R_{t+1}$, the marginal

\footnotetext{
${ }^{4}$ This assumption is commonly adopted in the works studying financial frictions. For example, [Bernanke et al., 1999] assumed that in each period there is a likelihood that the existing entrepreneurs exit.

${ }^{5}$ See [Gertler and Kiyotaki, 2015] for derivation details.
} 
cost of deposits. $\Omega_{t+1}$ can be thought of as a weighted average of marginal values of net worth for the exiting bankers $(1-\sigma)$ and surviving bankers $(\sigma)$. We can write the incentive constraint (30) $\varepsilon_{t}^{\kappa} \kappa Q_{t} S_{t} \leq V_{t}$ as

$$
\varepsilon_{t}^{\kappa} \kappa Q_{t} S_{t} \leq \mu_{t} Q_{t} S_{t}+v_{t} n_{t}
$$

When there is no restriction on raising deposit, $\mu_{t}=0$. This is because the unlimited arbitrage by banks will drive the excess return $\left(R_{t+1}^{l}-R_{t+1}\right)$ to zero. However, as long as the constraint is binding, limits to arbitrage will lead to a positive expected excess return, $R_{t+1}^{l}>R_{t+1}$. In the model, I restrict that the excess marginal value from continuing to manage assets is positive but less than the marginal benefit from diverting funds, that is,

$$
0<\mu_{t}<\varepsilon_{t}^{\kappa} \kappa
$$

When $0<\mu_{t}<\varepsilon_{t}^{\kappa} \kappa$, the incentive constraint is binding:

$$
\varepsilon_{t}^{\kappa} \kappa Q_{t} S_{t}=\mu_{t} Q_{t} S_{t}+v_{t} n_{t}
$$

This means that $\phi_{t}$, the maximum asset-to-net worth ratio (leverage) is

$$
\phi_{t}=\frac{Q_{t} S_{t}}{n_{t}}=\frac{v_{t}}{\varepsilon_{t}^{\kappa} \kappa-\mu_{t}}
$$

Equation (37) tells that the maximum deposit the bank with net worth $n_{t}$ is $\phi_{t} n_{t}$. The agency problem between the depositors and the banking sector leads to an endogenous leverage constraint for the banks. Furthermore, the tighter the constraint is, the larger the excess return $\left(R_{t+1}^{l}-R_{t+1}\right)$ is. In the model, a decline in asset value caused by house prices will tighten the incentive constraint, and thus the excess return (risk premium) is much higher in the crisis period.

Let $n_{t}^{e}$ denote the net worth for the existing bankers, and $n_{t}^{n}$ for the newly entered bankers. It is assumed that the patient households receive the assets $(1-\sigma) Q_{t-1} S_{t-1}$ of the existing bankers at the end of period $t$, and they transfer a fraction $\omega /(1-\sigma)$ of the receiving transfer to the newly entered bankers in the beginning of the next period. Thus, the total net worth at the beginning of the period $t$ is 6

$$
n_{t}=n_{t}^{n}+n_{t}^{e}
$$

with

$$
n_{t}^{e}=\sigma\left[\left(R_{t+1}^{l}-R_{t}\right) \phi_{t}+R_{t}\right] n_{t-1}^{e},
$$

and

$$
n_{t}^{n}=\frac{\omega}{1-\sigma}(1-\sigma) Q_{t-1} S_{t-1}=\omega Q_{t-1} S_{t-1} .
$$

\footnotetext{
${ }^{6} \omega$ is set to a very small number 0.002 as [Gertler and Karadi, 2011].
} 


\subsection{Goods and House Producers}

\subsubsection{Capital Producers}

Capital producers operate in a competitive market. Capital production is assumed to be subject to an investment-specific shock, $\tau_{t}^{k}$. Capital producers purchase the final goods from retailers, $i_{t}^{k}$, and produce efficient investment goods, $\tau_{t}^{k} i_{t}^{k}$. I assume that capital producers face investment adjustment costs $S\left(i_{t}, i_{t-1}\right)$, such that in steady state $S=S^{\prime}=0$ and $S^{\prime \prime}=\chi^{k}>0$, and $\chi^{k}>0$ is an investment adjustment cost parameter. At the end of period $t$. The capital producer solves for $i_{t}^{k}$ to maximize

$$
\max E_{t} \sum \beta^{p} \Lambda_{t, t+1}\left\{P_{t}^{k}\left[\tau_{t}^{k}-S_{k}\left(\frac{i_{t}^{k}}{i_{t-1}^{k}}\right)\right] i_{t}^{k}-P_{t} i_{t}^{k}\right\}
$$

where $\Lambda_{t, t+1}=\lambda_{1, t+1}^{p} / \lambda_{1, t}^{p} \cdot{ }^{7}$ Let the functional form for $S\left(i_{t}^{k}, i_{t-1}^{k}\right)$ be

$$
S\left(i_{t}^{k}, i_{t-1}^{k}\right)=0.5 \chi^{k}\left(\frac{i_{t}^{k}}{i_{t-1}^{k}}-1\right)^{2} .
$$

The first order condition for $i_{t}^{k}$ is

$$
\tau_{t}^{k} q_{t}^{k}=1+0.5 q_{t}^{k} \chi^{k}\left(\frac{i_{t}^{k}}{i_{t-1}^{k}}-1\right)^{2}+q_{t}^{k} \chi^{k}\left(\frac{i_{t}^{k}}{i_{t-1}^{k}}-1\right)\left(\frac{i_{t}^{k}}{i_{t-1}^{k}}\right)-\beta_{p} \Lambda_{t, t+1} q_{t+1} \chi^{k}\left(\frac{i_{t+1}^{k}}{i_{t}^{k}}-1\right)\left(\frac{i_{t+1}^{k}}{i_{t}^{k}}\right)^{2}
$$

where $\tau_{t}^{k}$ is a shock on the investment technology and follows the first-order autoregressive process:

$$
\log \tau_{t}^{k}=\rho^{\tau^{k}} \log \tau_{t-1}^{k}+\zeta_{t}^{\tau^{k}}, \zeta_{t}^{\tau^{k}} \sim \text { i.i.d.N }\left(0, \sigma_{\epsilon^{\tau k}}^{2}\right) .
$$

The aggregate stock of capital evolves as follows:

$$
k_{t}=\left(1-\delta^{k}\right) k_{t-1}+\tau_{t}^{k} i_{t}^{k}
$$

\subsubsection{House Producers}

Similarly, new houses are produced by perfectly competitive firms. The production is subject to housing investment adjustment costs $S_{h}\left(i_{t}^{h}, i_{t-1}^{h}\right)$, such that in the steady state $S=S^{\prime}=0$ and $S^{\prime \prime}=\chi^{h}>0$, and $\chi^{h}>0$ is an investment adjustment cost parameter. The house producer solves for $i_{t}^{h}$ to maximize

$$
\max E_{t} \sum \beta^{p} \Lambda_{t, t+1}\left[P_{t}^{h} h_{t}^{n}-P_{t} i_{t}^{h}\right]
$$

The production of new house follows the following technology

$$
h_{t}^{n}=\left(1-S_{h}\left(\frac{i_{t}^{h}}{i_{t-1}^{h}}\right)\right) i_{t}^{h},
$$

\footnotetext{
${ }^{7}$ It is assumed that capital producers, house producers and retailers use the patient households' discount factor in their stochastic discount factor calculation.
} 
Again, we assume that the functional form for $S\left(i_{t}^{h}, i_{t-1}^{h}\right)$ is

$$
S\left(i_{t}^{h}, i_{t-1}^{h}\right)=0.5 \chi^{h}\left(\frac{i_{t}^{h}}{i_{t-1}^{h}}-1\right)^{2} .
$$

The first order condition for $i_{t}^{h}$ is

$$
q_{t}=1+0.5 q_{t} \chi^{h}\left(\frac{i_{t}^{h}}{i_{t-1}^{h}}-1\right)^{2}+q_{t} \chi^{h}\left(\frac{i_{t}^{h}}{i_{t-1}^{h}}-1\right)\left(\frac{i_{t}^{h}}{i_{t-1}^{h}}\right)-\beta \Lambda_{t, t+1} q_{t+1} \chi^{h}\left(\frac{i_{t+1}^{h}}{i_{t}^{h}}-1\right)\left(\frac{i_{t+1}^{h}}{i_{t}^{h}}\right)^{2} .
$$

The total house stock evolves

$$
h_{t}=\left(1-\delta^{h}\right) h_{t-1}+i_{t}^{h}
$$

\subsubsection{Wholesale Goods Sector}

The wholesale goods are produced by using the following constant-return-to-scale production function technology

$$
y_{t}=A_{t} k_{t}^{\gamma}\left(\left(n_{p, t}\right)^{\alpha}\left(n_{i p, t}\right)^{1-\alpha}\right)^{1-\gamma}
$$

where $A_{t}$ is a shock to technology, which follows

$$
\log A_{t}=\rho^{A} \log A_{t-1}+\varsigma_{t}^{A} .
$$

It is assumed that the wholesale goods producers acquire capital from capital producers at the end of $t-1$ for use in production in period $t$. After production, they sell the undepreciated capital in the open market.

The firms borrow from the financial intermediaries for capital acquisition at the rate $R_{t}^{l}$. The firms are competitive and earn zero profits, and at the end of period they pay out the realized return to capital to the intermediaries:

$$
E_{t} R_{t+1}^{l}=\frac{E_{t}\left[r_{t+1}^{k}+q_{t+1}^{k}(1-\delta)\right]}{q_{t}^{k}}
$$

where $r_{t+1}^{k}$ is defined below. Thus in each period, these firms maximize the profit by choosing $k_{t}, n_{p, t}$ and $n_{i p, t}$

$$
\max p_{t}^{w} y_{t}-r_{t}^{k} k_{t}-w_{p, t} n_{p, t}-w_{i p, t} n_{i p, t}
$$

and the first-order conditions are

$$
\begin{gathered}
p_{t}^{w} \gamma \frac{y_{t}}{k_{t}}=r_{t}^{k}, \\
p_{t}^{w} \alpha(1-\gamma) \frac{y_{t}}{n_{p, t}}=w_{p, t},
\end{gathered}
$$

and

$$
p_{t}^{w}(1-\alpha)(1-\gamma) \frac{y_{t}}{n_{i p, t}}=w_{i p, t}
$$


where $p_{t}^{w}$ is the price for the wholesale goods.

\subsubsection{Retailers}

There are continuum of retailers of mass 1 , indexed by $j$. They buy intermediate goods from wholesale goods producers at $p_{t}^{w}$ in a competitive market and differentiate the goods at no costs into $y_{t}(i)$, and sell $y_{t}(j)$ at the price $p_{t}(j)$.

The final goods $y_{t}$ is the composite of individual variety,

$$
y_{t}=\left[\int_{0}^{1} y_{t}(j)^{\frac{\varepsilon-1}{\varepsilon}} d j\right]^{\frac{\varepsilon}{\varepsilon-1}} .
$$

The price index that minimizes the final producers' cost function is

$$
p_{t}=\left[\int_{0}^{1} p_{t}(j)^{1-\varepsilon} d j\right]^{\frac{1}{1-\varepsilon}} .
$$

The demand function faced by each retailer is given by

$$
y_{t}(j)=\left(\frac{p_{t}(j)}{p_{t}}\right)^{-\varepsilon_{t}} y_{t} .
$$

Following [Calvo, 1983], in each period, only a fraction $1-\nu$ of retailers reset their prices, while the remaining retailers keep their prices unchanged. The retailer chooses $p_{i, t}$ to maximize its expected real total profit over the periods during which its prices remain fixed:

$$
E_{t} \Sigma_{i=0}^{\infty} \nu \Delta_{i, t+i}^{p}\left[\left(\frac{p_{i, t}}{p_{i, t+i}}\right) y_{t+i}-m c_{t+i} y_{t+i}(i)\right]
$$

where $m c_{t}$ is the real marginal cost, namely, the price of wholesale goods relative to the price of sectoral final goods $\left(p_{t}^{w} / p_{t}\right) . \Delta_{t, i}^{p} \equiv \beta_{p} \lambda_{1, t+1}^{p} / \lambda_{1, t}^{p}$ is the stochastic discount factor. Let $p_{t}^{*}$ be the optimal price chosen by all firms adjusting at time $t$.

The first-order condition for the optimal price is:

$$
p_{i, t}^{*}=\left(\frac{\varepsilon}{\varepsilon-1}\right) \frac{E_{t} \sum_{s=0}^{\infty} \nu^{s} \Delta_{s, t+s}^{p} m c_{t+1} y_{t+i}\left(\frac{1}{p_{t+i}}\right)^{-\varepsilon}}{E_{t} \sum_{s=0}^{\infty} \nu^{s} \Delta_{s, t+s}^{p} y_{t+i}\left(\frac{1}{p_{t+i}}\right)^{1-\varepsilon}} .
$$

The aggregate price evolves according to:

$$
p_{t}=\left[\nu p_{t-1}^{1-\varepsilon}+(1-\nu)\left(p_{t}^{*}\right)^{1-\varepsilon}\right]^{\frac{1}{1-\varepsilon}} .
$$




\subsection{Government}

Government expenditures are financed by lump sum tax

$$
g_{t}=t_{t}
$$

where $g_{t}$ follows an AR(1) process,

$$
\log g_{t}=\left(1-\rho^{g}\right) \log g_{s s}+\rho^{g} \log g_{t-1}+\zeta_{t}^{g}, \zeta_{t}^{g} \sim \text { i.i.d.N }\left(0, \sigma_{\zeta^{g}}^{2}\right),
$$

where $g_{s s}=g_{y} y_{s s}$ and $g_{y}$ is the fraction of GDP spent on government spending.

\subsection{Monetary Policy}

The central bank is assumed to operate according to the standard Taylor Rule. The central bank adjusts the nominal interest rate, $R_{t}$, in response to deviations of inflation, $\pi_{t}$, from its steady-state value, $\pi$, and output, $y_{t}$, from its steady-state level, $y$.

$$
\frac{R_{t}}{R}=\left(\frac{R_{t-1}}{R}\right)^{\rho_{r}}\left(\left(\frac{\pi_{t}}{\pi}\right)^{\rho_{\pi}}\left(\frac{y_{t}}{y}\right)^{\rho_{y}}\right)^{1-\rho_{r}} e^{\zeta_{t}^{m}}
$$

where $R, \pi$, and $y$ are the steady-state values of $R_{t}, \pi_{t}$ and $y_{t}$, and $\zeta_{t}^{m}$ is a monetary policy shock which follows

$$
\zeta_{t}^{m} \sim \text { i.i.d. } N\left(0, \sigma_{\zeta^{m}}\right) .
$$

$\rho_{\pi}, \rho_{y}$ and $\rho_{r}$ are policy coefficients chosen by the central bank.

\subsection{Equilibrium}

The equilibrium is an allocation $\left(h_{p, t}, h_{i p, t}, n_{p, t}, n_{i p, t}, c_{p, t}, c_{i p, t}, i_{p, t}, i_{i p, t}, d_{t}, l_{t}, y_{t}\right)_{t=0}^{\infty}$ together with the sequence of prices $\left(w_{p, t}, w_{i p, t}, q_{t}, P_{t}, P_{t}^{*}, p^{w}\right)_{t=0}^{\infty}$ satisfying the first-order conditions, budget constraints, borrowing constraint, and following market clearing conditions:

Goods market:

$$
c_{p, t}+c_{i p, t}+q_{t}\left(i_{p, t}^{h}+i_{i p, t}^{h}\right)+q_{t}^{k} i_{t}^{k}+0.5 \chi^{k}\left(\frac{i_{t}^{k}}{i_{t-1}^{k}}-1\right)^{2}+0.5 \chi^{h}\left(\frac{i_{t}^{h}}{i_{t-1}^{h}}-1\right)^{2}+g_{t}=y_{t},
$$

and housing market:

$$
h_{i p, t}+h_{p, t}=h_{t}
$$

\section{Data and Estimation}

In order to provide a quantitative answer to the questions raised in the beginning of the paper, I estimate the model using a Bayesian approach. In what follows, I present the data, the calibrated parameters, the priors and the estimation results. 


\subsection{Data}

I estimate the model using U.S. quarterly data from 1991Q1 to 2014Q1. I use eight time series as observables since the model allows for eight shocks. The time series are: output, investment, consumption, government spending, nominal interest rate, inflation, risk premium and mortgage loan. Appendix $\mathrm{C}$ describes the data construction. For the real variables, I detrend the logarithm of each variable using a quadratic trend. The nominal variables are demeaned. The detrended and demeaned data are plotted in Figure 2.

Figure 2: Data Used in Estimation 1991Q1-2014Q1
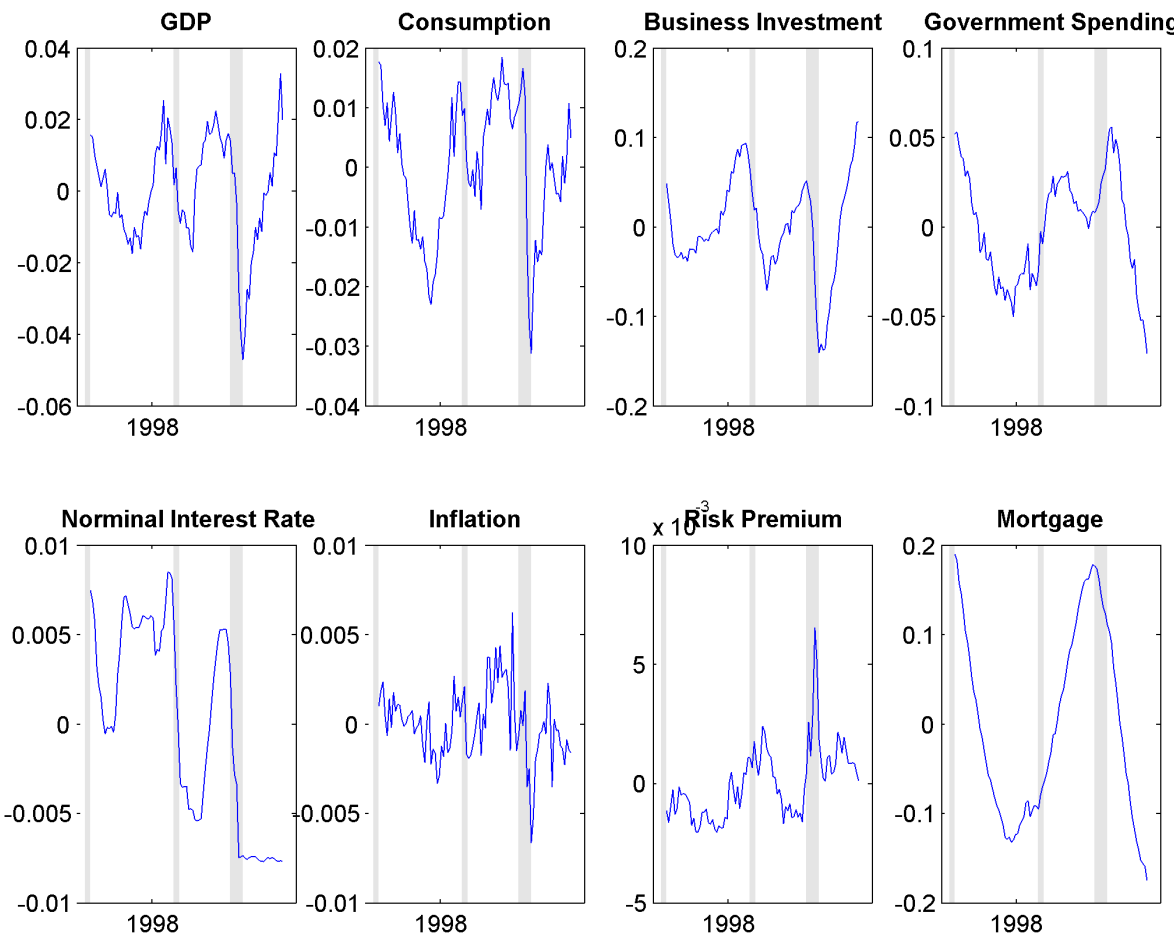

All the real variables are in percentage deviations from the their trends and all the nominal variables are in percentage deviations from their means.

\subsection{Calibrated Parameters}

Table 1 summarizes the calibrated parameters. I set the discount factor for the patient households to 0.9925 , which implies an annualized steady-state deposit rate $R_{t}$ of 3 percent. For the impatient households, I set the discount factor at 0.94 which, together with the other parameters, implies an annualized steady-state lending rate $R_{t}^{l}$ of 4 percent. This gives me the steady-state annual risk premium of 100 basis points, the value used in [Gertler and Karadi, 2011]. I set the weight on leisure in the household utility function $\psi$ at 1 since it only affects the scale of the economy. I also 
Table 1: Calibrated Parameters

\begin{tabular}{|c|c|c|}
\hline \multicolumn{3}{|l|}{ Household } \\
\hline Discount factor for patient households & $\beta^{p}$ & 0.9925 \\
\hline Discount factor for impatient households & $\beta^{i p}$ & 0.94 \\
\hline Relative utility weight of labour & $\psi$ & 1 \\
\hline Relative utility weight of housing & $\phi$ & 0.25 \\
\hline Inverse Frisch elasticity of labour supply & $\eta$ & 1 \\
\hline House depreciation rate & $\delta_{h}$ & 0.01 \\
\hline Collateral constraint parameter & $\theta$ & 0.85 \\
\hline Persistence of household debt & $\rho^{l}$ & 0.95 \\
\hline \multicolumn{3}{|l|}{ Financial intermediaries } \\
\hline Fraction of assets that can be diverted & $\kappa$ & 0.382 \\
\hline Survival rate of the bankers & $\sigma$ & 0.97 \\
\hline \multicolumn{3}{|l|}{ Intermediate good producers } \\
\hline Capital share & $\alpha$ & 0.33 \\
\hline Share of patient households labour income & $\gamma$ & 0.64 \\
\hline Capital depreciation rate & $\delta$ & 0.025 \\
\hline \multicolumn{3}{|l|}{ Government } \\
\hline Fraction of GDP spent on government spending & $g$ & 0.20 \\
\hline
\end{tabular}

pick a Frisch elasticity of labor supply $(1 /)$ at $1 .^{8}$

The depreciation rate for houses $\delta_{h}$ is set to 0.01 , matching the target of the ratio of residential investment to GDP of 5 percent. I set the loan-to-value ratio $\theta$ to 0.85 , which is suggested to be the average value for the first time home buyers by [Duca et al., 2011]. I set the housing preference parameters $\phi$ to 0.25 , together with $\delta_{h}$ and $\theta$, implying that the average ratio of market value of housing stock to GDP ratio is 1.3 at an annualized basis.

For the production function, I set the capital share $\alpha$ to 0.33 , and wage share of the impatient households $(1-\gamma)$ to 36 percent, which is the estimate in [Iacoviello, 2005]. ${ }^{9}$ The depreciation rate for capital is set to 0.025 . I follow [Gertler and Karadi, 2011] for setting the parameters for the banking sector. The fraction of capital that can be diverted $\kappa$ is set to 0.382 , which gives us the steady state leverage about $4 .^{10}$ The survival rate of the banks $\sigma$ is set to 0.97 , suggesting that the average duration for a bank to stay in business is about 10 years.

\footnotetext{
${ }^{8}$ This value is a compromise between microeconometric estimates of the Frisch labor supply (0 to 0.5$)$ and the values used by macroeconomists to calibrate general equilibrium models (2-4).

${ }^{9}$ Other studies, such as [Hall, 2011], and [Justiniano et al., 2015] suggest that the fraction of the liquidity constraint households is much higher, around 60 percent.

${ }^{10} \mathrm{As}$ in [Gertler and Karadi, 2011], $\kappa$, is chosen to deliver a leverage ratio that is a compromise between the high leverage ratio for investment bank and commercial bank (20-40) and the low one for the corporate and non-corporate business sectors (2).
} 


\subsection{Priors}

I estimate 7 structural parameters, and persistence and standard deviations for 8 exogenous shocks. The priors are displayed in Table 2. I set the priors as loose as possible, and most of them are quite standard.

The Taylor rule inflation $\rho_{\pi}$ and output coefficients $\rho_{y}$ are assumed to follow a gamma distribution with mean 1.5 and standard deviation 0.25 , and a normal distribution with mean 0.125 and standard deviation 0.15 , respectively. For the interest rate smoothing parameter $\rho_{r}$, I assume that it follow a beta distribution with mean 0.8 and standard deviation 0.2 . The habit persistence parameter $b$ is assumed to fluctuate around 0.6 with a standard error of 0.15 . The prior on the adjustment cost parameter for business and housing investment $\chi^{k}, \chi^{k}$ are set to follow a gamma distribution which is around mean 4 , and 30 with a standard error of 1.5, respectively. For Calvo parameter $v$, I assume that it follows a beta distribution of mean 0.6 and standard deviation of 0.15 .

The standard errors of the innovations are assumed to follow an inverse-gamma distribution with a mean of 0.005 and two degrees of freedom. The persistence of the AR(1) processes is beta distributed with mean 0.8 and standard deviation 0.2 .

\subsection{Estimated parameters and smoothed shocks}

The last column of Table 2 reports the modes for the estimated model parameters. The Calvo parameter $v$ is found to be 0.71 , suggesting price changes every 3.4 quarters. The habit persistence parameter $b$ is estimated at 0.67 . The investment adjustment costs parameters $\chi^{k}$ and $\chi^{h}$ are found to be 1.86 and 30.9 respectively. For the monetary policy parameters, the estimates fall within the standard range: the Taylor rule inflation and output parameters are estimated at 2.53 and 0.05 respectively, and the interest rate smoothing parameter is estimated at 0.76 .

For the shock parameters, the housing demand shocks are found to be the most volatile with $\zeta_{t}^{h}=0.19$. The loan-to-value ratio shocks exhibits a large volatility as well with $\zeta_{t}^{\theta}=0.13$. The estimated standard deviations for the remaining parameters are ranging from 0.0018 to 0.0163 . The government spending shocks are the most persistent shocks with $\rho^{g}=0.99$. The banking sector shocks and housing demand shocks are also quite persistent with $\rho^{\kappa}=0.98$ and $\rho^{h}=0.97$.

Figure 3 shows the estimated smoothed values for the shock processes considered in the model. The shaded areas are the NBER recessions. The striking feature is the extreme high value in the banking sector shock during the most recent recession. In addition, the recent recession shows up in the low values in the consumption goods demand shock, the housing demand shock, and the investment-specific shock. 
Table 2: Estimation Results

\begin{tabular}{|c|c|c|c|c|c|}
\hline \multicolumn{2}{|c|}{ Parameter } & \multicolumn{3}{|c|}{ Prior Distribution } & Mode \\
\hline \multicolumn{6}{|c|}{ Structural Parameters } \\
\hline$\rho_{r}$ & Taylor rule smoothing & beta & 0.80 & 0.2 & 0.76 \\
\hline$\rho_{\pi}$ & Taylor rule inflation & gamm & 1.5 & 0.25 & 2.53 \\
\hline$\rho_{y}$ & Taylor rule output & norm & 0.125 & 0.15 & 0.05 \\
\hline$v$ & Calvo parameter & beta & 0.6 & 0.15 & 0.71 \\
\hline$b$ & Habit persistence & beta & 0.6 & 0.2 & 0.67 \\
\hline$\chi^{k}$ & Business investment adj. costs & gamm & 4 & 1.5 & 1.86 \\
\hline$\chi^{h}$ & Housing investment adj. costs & gamm & 30 & 1.5 & 30.9 \\
\hline \multicolumn{6}{|c|}{ Shock Processes } \\
\hline$\rho^{A}$ & Persistence, technology shock & beta & 0.8 & 0.2 & 0.76 \\
\hline$\rho^{c}$ & Persistence, consumption demand shock & beta & 0.8 & 0.2 & 0.59 \\
\hline$\rho^{h}$ & Persistence, housing demand shock & beta & 0.8 & 0.2 & 0.97 \\
\hline$\rho^{\theta}$ & Persistence, LTV shock & beta & 0.8 & 0.2 & 0.78 \\
\hline$\rho^{\kappa}$ & Persistence, banking sector shock & beta & 0.8 & 0.2 & 0.98 \\
\hline$\rho^{g}$ & Persistence, government shock & beta & 0.8 & 0.2 & 0.99 \\
\hline$\rho^{\tau^{k}}$ & Persistence, investment specific shock & beta & 0.8 & 0.2 & 0.82 \\
\hline$\zeta_{t}^{a}$ & Std., technology shock & invg & 0.005 & 2 & 0.0083 \\
\hline$\zeta_{t}^{m}$ & Std., monetary policy shock & invg & 0.005 & 2 & 0.0018 \\
\hline$\zeta_{t}^{c}$ & Std., consumption demand shock & invg & 0.005 & 2 & 0.0273 \\
\hline$\zeta_{t}^{h}$ & Std., housing demand shock & invg & 0.005 & 2 & 0.1977 \\
\hline$\zeta_{t}^{\theta}$ & Std., LTV shock & invg & 0.005 & 2 & 0.1346 \\
\hline$\zeta_{t}^{\kappa}$ & Std., banking sector shock & invg & 0.005 & 2 & 0.0211 \\
\hline$\zeta_{t}^{g}$ & Std., government spending shock & invg & 0.005 & 2 & 0.0083 \\
\hline$\zeta_{t}^{\tau^{k}}$ & Std., investment shock & invg & 0.005 & 2 & 0.0163 \\
\hline
\end{tabular}

Notes: invg denotes the inverse gamma distribution 
Figure 3: Smoothed Shocks 1991Q1-2014Q1
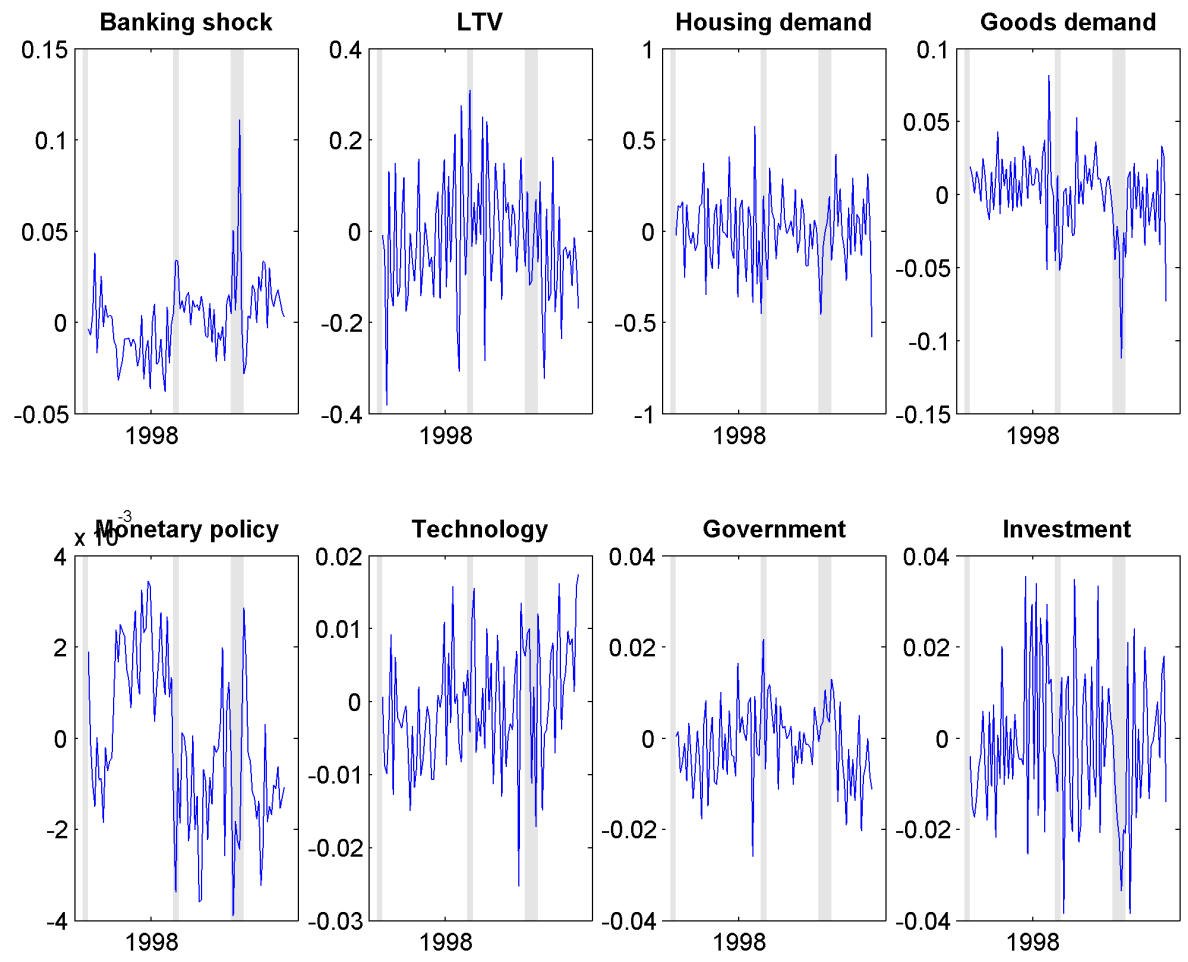

All the variables are in percentage deviations from their steady-state values.

\section{Model Analysis}

\subsection{Model performance}

In this section, I asses the model's performance by comparing the predicted volatilities of the key macro variables with the ones observed in the data, and some most relevant correlations. The first part of Table 3 reports the relative volatilities (normalized by the standard deviation of output) of the key variables in the model and in the data; the second part of the table reports some key correlations. In terms of matching the standard deviations, except for consumption, the model's performance is quite decent. The predicted volatility in business investment $\left(i^{k}\right)$ is quite close to that in the data (3.9 in the model versus 3.7 in the data). The model predicts high volatilities in housing investment $\left(i^{h}\right)$, housing prices $(q)$ and mortgage loans $(l)$, although it over-predicts the volatilities in housing investment and mortgage debt, and under-predicts the fluctuations in housing prices. The predicted volatilities in the remaining nominal variables (nominal interest rate $R$, inflation $\pi$, and risk premium $s$ ) are quite close to those in the data as well.

The second panel in Table 3 assesses the performance of the model by comparing some key correlations generated by the model with the ones observed in the data. The model matches well with the fact that risk premium is countercyclical (-0.34 in the model versus -0.31 in the data). The 
model also captures well the negative correlation between housing price and risk premium (-0.17 in the model versus -0.22 in the data). The model predicts positive correlations between output and housing price as well as between housing price and mortgage debt, although both of them are under-predicted.

Table 3: Standard Deviations and Correlations-Model vs. Data

\begin{tabular}{|c|c|c|c|c|c|c|c|c|c|c|}
\hline SD & & $y$ & $c$ & $i^{k}$ & $i^{h}$ & $q$ & $l$ & $R$ & $\pi$ & $s$ \\
\hline & Data & 1 & 0.8 & 3.7 & 12 & 9.1 & 7.1 & 0.4 & 0.1 & 0.1 \\
\hline & Model & 1 & 1.7 & 3.9 & 18 & 4.4 & 11.9 & 0.13 & 0.1 & 0.13 \\
\hline Correlation & & & $y, s$ & & $q, s$ & & $y, q$ & & $q, l$ & \\
\hline & Data & & 0.31 & & 0.22 & & 0.52 & & 0.76 & \\
\hline & Model & & 0.34 & & 0.17 & & 0.30 & & 0.15 & \\
\hline
\end{tabular}

\subsection{Variance decomposition and historical decomposition}

Forecast error variance decomposition gives information regarding how important an individual shock is. Table 4 reports the variance decomposition at the eight quarters forecast horizon. There are a few things worth mentioning here: first, almost half of the variations in output are explained by the banking sector shock and housing demand shock, the remaining half are split among goods demand, monetary policy, technology and investment-specific shocks. Second, housing demand shocks accounts for about half of the fluctuations in consumption, and almost all the variations in housing investment and housing prices. The latter two variables exhibit very large variations during the sample period. The result suggests that to match these large variations, the model largely relies the exogenous housing demand shock instead of the intrinsic properties of the model. Third, the banking sector shocks account for more than half of the variations in risk premium, and about 30 per cent in business investment. Lastly, the variations in household debt are mainly explained by loan-to-value shock and housing demand shock.

In order to find the driving forces for the decline in GDP in the U.S. during the Great Recession period, I conduct historical decomposition for GDP for the period of 2006Q1-2012Q1 and find that the banking sector shocks and housing demand shocks (together with consumption demand shocks) were the main shocks that caused the deep decline in output (Figure 4). Table 5 offers a more detailed description of the contributions of these three shocks to the decline in output from 2009Q1 to 2009Q4 - the period that the U.S. economy experiences the steepest decline. At the tough 2009Q3, GDP declines about 4.7 per cent. The banking sector shocks and housing demand shocks account for more than half of the decline (1.4 percentage points decline and 1.2 percentage points decline respectively). The consumption demand shocks account for about 2.2 percentage points. 
Table 4: Variance Decomposition - Business Cycle Frequency

\begin{tabular}{llllllllr}
\hline \hline & Banking & LTV & Housing & Con. & Mon. & Tech. & Gov. & Inv. \\
\hline Output & 16.31 & 0.75 & 29.57 & 11.04 & 15.69 & 15.1 & 1.36 & 10.18 \\
Consumption & 1.17 & 0.36 & 54.5 & 40.22 & 0.29 & 1.99 & 1.24 & 0.22 \\
Business inv. & 30.71 & 1.95 & 7.18 & 1.29 & 16.05 & 4.72 & 0.01 & 38.1 \\
Housing inv. & 0.24 & 0 & 99.27 & 0.05 & 0.16 & 0.18 & 0.1 & 0 \\
House prices & 1.02 & 0.01 & 97.71 & 0.21 & 0.34 & 0.39 & 0.05 & 0.27 \\
HH debt & 0.07 & 66 & 33.24 & 0.22 & 0.44 & 0 & 0 & 0.02 \\
Nor. int. rate & 26.78 & 0.14 & 13.51 & 7.89 & 15.52 & 18.74 & 0.04 & 17.38 \\
Inflation & 11.13 & 0.14 & 13.72 & 5.01 & 34.01 & 28.4 & 0.03 & 7.57 \\
Risk premium & 55.52 & 1.48 & 14.13 & 4.2 & 11.25 & 6.98 & 0.04 & 6.41 \\
Assets prices & 14.05 & 0.23 & 11.36 & 2.7 & 11.65 & 8.19 & 0.01 & 51.81 \\
\hline
\end{tabular}

Table 5: Historical Decomposition - 2006Q1-2012Q1

\begin{tabular}{lllll}
\hline \hline Contribution to output & 2009Q1 & 2009Q2 & 2009Q3 & 2009Q4 \\
\hline Banking sector shocks & -1.32 & -1.59 & -1.41 & -1.14 \\
Housing demand shocks & -1.38 & -0.93 & -1.15 & -1.07 \\
Consumption demand shocks & -1.89 & -2.15 & -2.22 & -1.61 \\
\hline Data & -2.75 & -4.01 & -4.71 & -3.99 \\
\hline
\end{tabular}

\subsection{Model Dynamics and the Role of Banking Sector}

In this section, I illustrate the mechanism at work in the model and the role of the banking sector. Given the importance of the housing demand and banking sector shocks, I start with these two shocks. Figure 5 documents the impulse responses of the model to a housing demand shock. The size of the shock is set to a one standard deviation of the estimated shock process, and the direction of the shock is set to produce a decline in output. The blue line represents the response of the baseline model. The shock drives down the housing prices and household debt. Both asset prices and the net worth of the banks (Bank N) decline, resulting a rise in risk premium. Total investment (including both housing and business investments) declines, leading to a decline in output (although total consumption increases counterfactually). The counterfactual response in consumption is due to the switch of demand from housing to consumption goods. After the shock, the patient households reduces their housing demand gradually and increases their demand for consumption goods. In contrast, due to the collateral constraint, the impatient households have to reduce borrowing and cut back housing demand more drastically (leading to a larger counterfactual increase in consumption). Total housing demand and housing investment decline. The reduced borrowing from the impatient household leads a decline of the price of the assets (claims held by the banks). As a result, the net worth of the banking sector decreases and the constraint for the banks to raise deposits tightens. Risk premium rises due to the worsened banks' balance sheet positions. Both housing investment 
Figure 4: Sources of the Decline in Output 2006Q1-2012Q1: Historical Decomposition Evidence

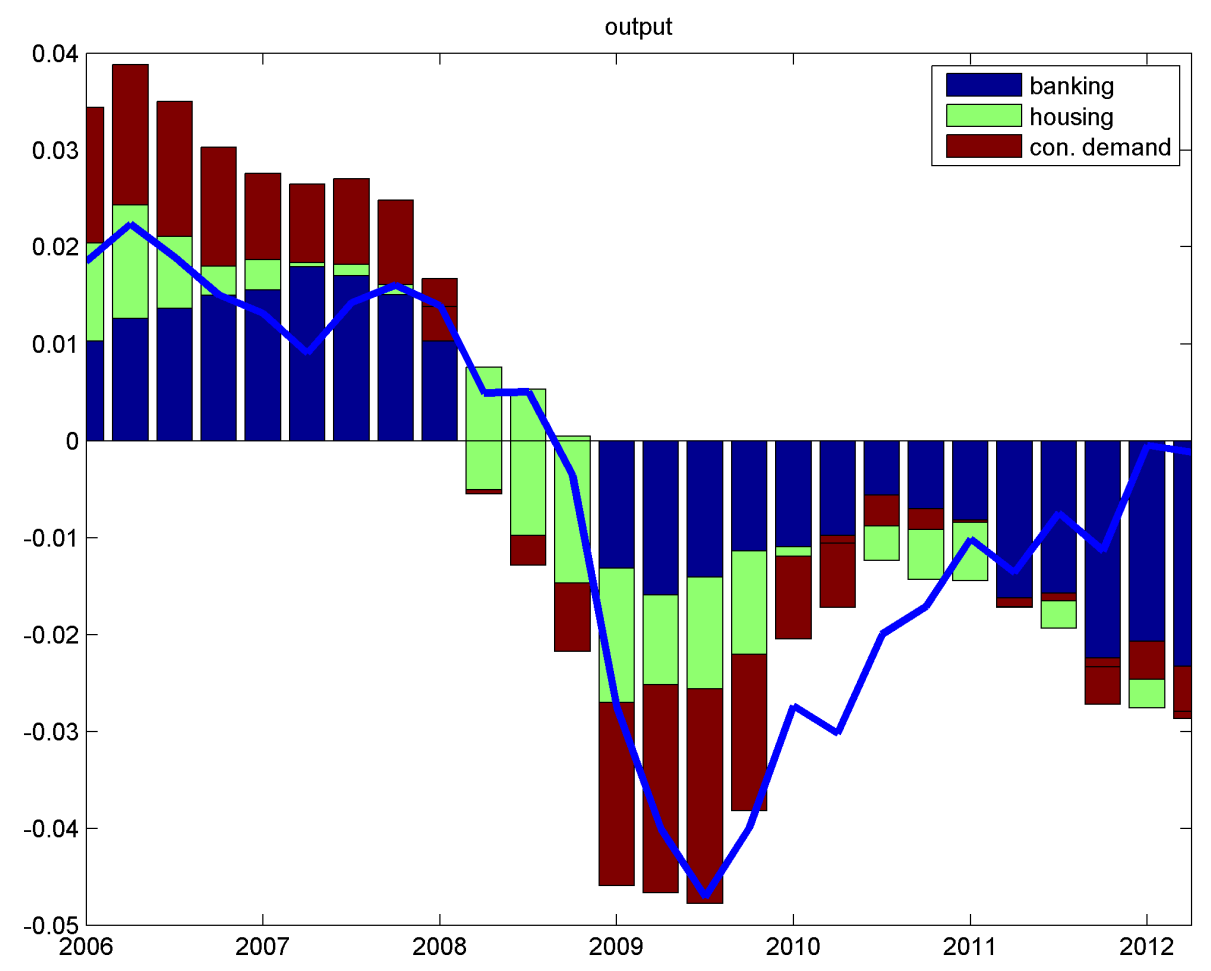

and business investment decline due the rise in borrowing costs, resulting a decline in output.

Figure 5 captures what has happened in the recent financial crisis in the U.S.: the collapse in the housing market deteriorates the balance sheet positions of the banks. Banks' net worth declines and mortgage risk premium rises significantly during the crisis. The red line represents the responses of the these variables in the model in which the banking sector is shut off. Compared to the model without the banking sector, output experiences a larger decline in the baseline model. This is because investment declines more due to the rise in risk premium in the baseline model.

Figure 6 shows the impulse response functions of the key variables after a banking sector shock. Given the sudden rise in the fraction of the funds the bank can divert, the incentive constraint of the bank tightens and risk premium rises. The increase in borrowing costs leads to declines in household borrowing. The decline in the borrowing ability for the impatient households leads to the decline in consumption goods and housing demands for the impatient households. However, for the patient households, the reduction in deposits leads to an increase in consumption goods and housing demands. At the aggregate level, the total consumption rises slightly after the shock. ${ }^{11}$ Housing

\footnotetext{
${ }^{11}$ In the model, when the patient households have to reduce deposits, they will either increase consumption or housing. To some shocks, for example, banking sector shocks, this would lead to the counterfactual rise in aggregate consumption in the downturn. One potential remedy to mitigate this effect is to introduce deposit insurance to break the tight link between deposits and banking assets.
} 
Figure 5: Effects of a Negative Housing Demand Shock
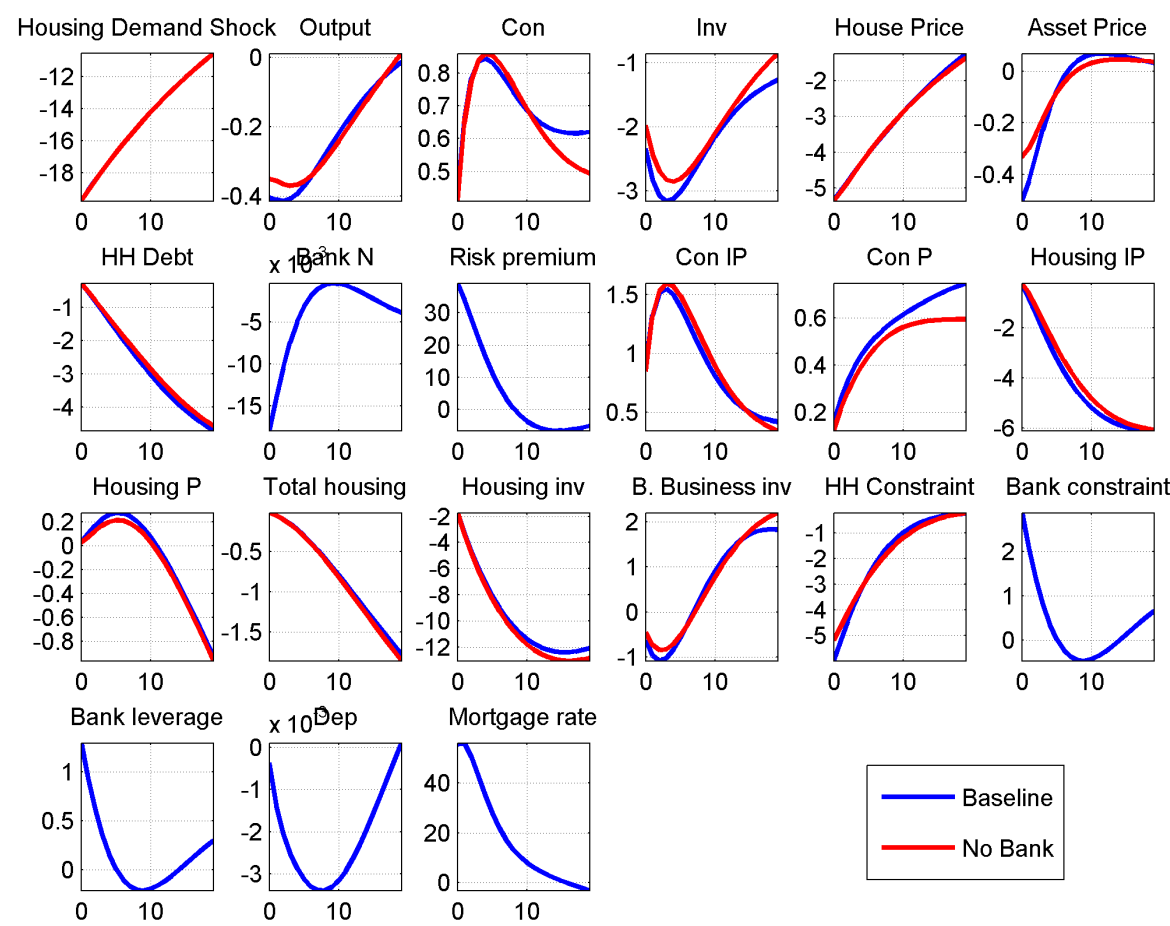

Mortgage rate
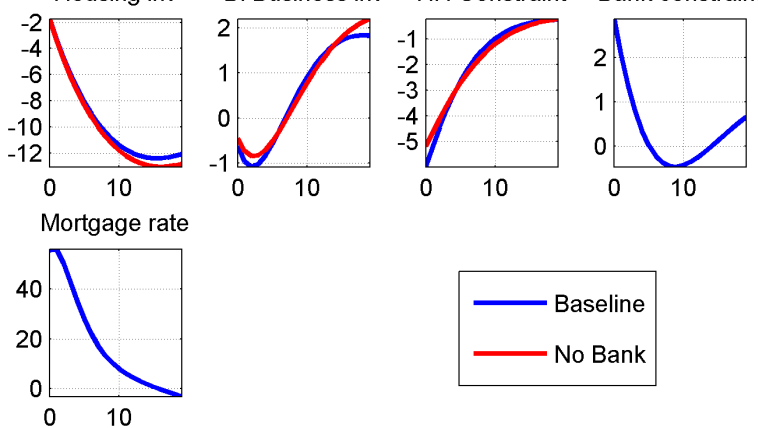

All the variables are in percentage deviations from their steady-state values except risk premium and mortgage risk which are in basis points. Bank $\mathrm{N}$ denotes bank net worth. IP denotes the impatient households. P denotes patient households. Dep denotes deposits.

price also rises due to the response from the patient households. The increase in risk premium also deters business borrowing, leading to a decline in business investment. Despite the counterfactual response in consumption, output declines after the shock due to the decline in investment.

For the remaining six shocks, I summarize the impulse response functions of the eight most important variables in Figure 7. As for the previous two shocks, the size of each shock is set to a one standard deviation of the estimated shock process and the direction of the shock is set to produce a decline in output. The blue line is for the baseline model and the red line is for the model without the banking sector. A positive LTV shock can be thought of as a shock that loosens lending standards. A sudden increase in the loan-to-value ratio encourages households' borrowing. This results in an increase in household debt, which in turn leads to an increase in banks'assets and net worth. The increase in net worth loosens the incentive constraint the bank faces, and as a result risk premium declines. However the decline in risk premium does not lead to an increase in investment. ${ }^{12}$ Output slightly declines due to the decline in investment. An contractionary monetary policy shock pushes down asset prices and banks' net worth, leading to a higher risk premium and a reduction in

\footnotetext{
${ }^{12}$ This might be because in the case of LTV shock, the rise in consumption depresses the demand for investment. As a result, investment decline despite the decline in risk premium.
} 
Figure 6: Effects of a Negative Banking Sector Shock
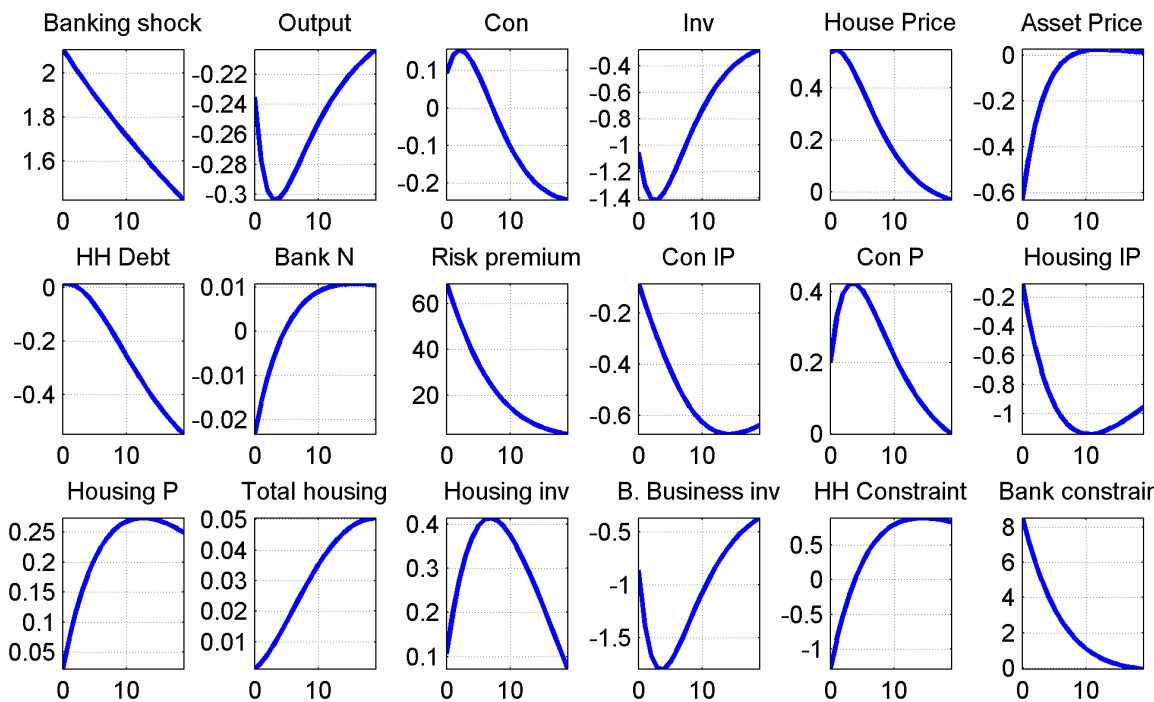

Bank constraint

Bank leverage
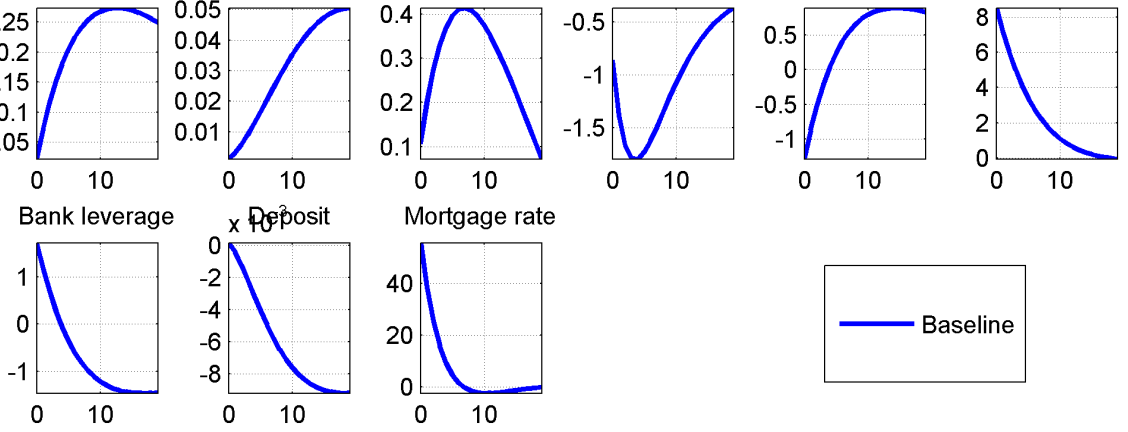

All the variables are in percentage deviations from their steady-state values except risk premium and mortgage risk which are in basis points. 
Figure 7: Effects of Other Key Shocks
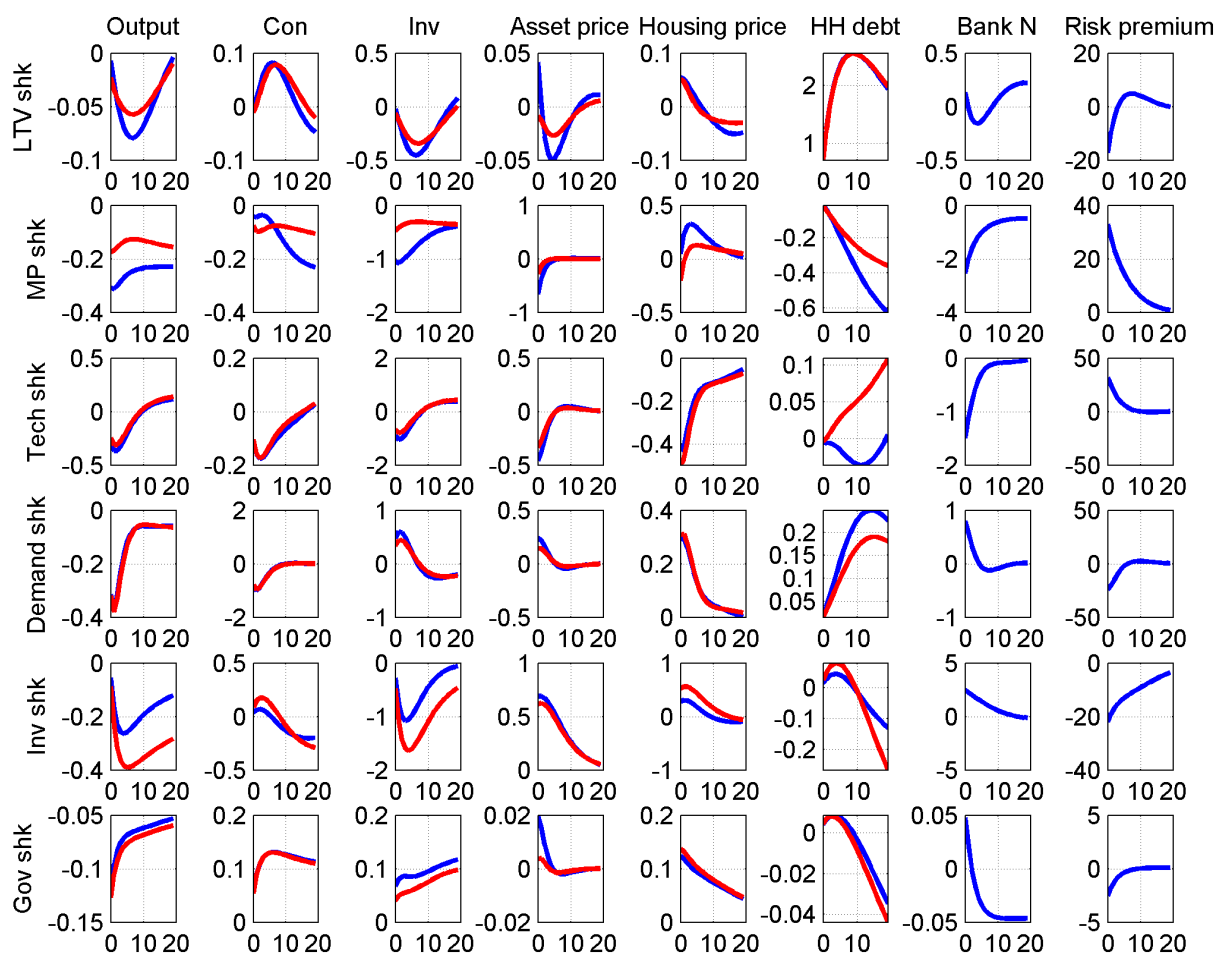

All the variables are in percentage deviations from their steady-state values except risk premium which is in basis points.

household debt. A negative technology shock also reduces asset prices and the net worth of the bank sector, resulting a countercyclical risk premium. Both house prices and household debt decline. A negative shock to the demand for consumption goods depresses the demand for consumption goods but increases the demand for investment goods. Thus, asset prices rise, leading to a rise in the net worth for the banking sector. A negative investment-efficiency shock has a similar effect on risk premium and banks' net worth to a negative demand shock: after the shocks, banks' net worth rises due to the rise in the prices of the assets held by the banks. The mechanism, however, is different. In the case of a negative investment-efficiency shock, the rise in asset prices is due to the decline in supply of capital caused by the reduced efficiency of transforming investment goods. The last row in Figure 7 is a shock that decreases government spending. Consumption and investment rise, leading a increase in asset prices and banks' net worth, which results in an decrease in risk premium.

Comparing the responses of these variables in the baseline model with the model without the banking sector, the impact of including a banking sector is most obvious when the economy is hit by monetary policy shock and investment-specific shock, although the banking sector amplifies one (monetary policy shock) while dampens the other (investment-specific shock). Compared to the model without the banking sector, a contractionary monetary policy shock generates a larger decline 
in output. This is because the decline in bank's net worth leads to a rise in risk premium, which further depresses the declines in asset prices and household debt. In contrast, to the investmentspecific shock, the financial frictions faced by the banking sector dampens the responses of the model. This is because in the model with banking sector, the increase in the banking sector's net worth and the decline in risk premium dampen the decline in investment and in turn, the decline in output.

\section{Effects of Unconventional Monetary Policy}

In the previous section, I show that the agency problem between banks and depositors leads to an endogenous capital constraint. The maximum leverage or assets to net worth ratio is

$$
\phi_{t}=\frac{A_{t}}{n_{t}}=\frac{v_{t}}{\kappa-\mu_{t}} .
$$

Now suppose that the central bank is willing to fund the fraction of $\psi_{t}$ of assets held by the financial intermediaries, that is,

$$
A_{t}^{g}=\psi_{t} A_{t}
$$

The government issues government debt $B$, which is equal to $\psi_{t} A_{t}$ to fund this activity. The total assets held by the financial intermediaries are

$$
A_{t}^{t}=\phi_{t} n_{t}+\psi_{t} A_{t}
$$

Thus, credit injection from the central bank increases the total asset held by the bank. Given that only private assets held by banks are constrained, this is equivalent to increasing banks' ability of raising deposits. The effects of the credit policy are shown in Figures 8 and 9. Figure 8 shows the effect of credit intervention after a housing demand shocks. The additional credit injected by the central bank relaxed the incentive constraint, thus risk premium rises by less in the credit policy model. Neither housing investment nor housing price, however, is affected by the change in risk premium. This is because both of them are mainly driven by the exogenous housing demand shock, and thus the dynamics of these two variables are quite similar in the baseline model and the model with credit policy. The impact of credit intervention is mainly on business investment, which declines by less in the model with credit policy. Figure 9 shows the effect of credit intervention to a banking sector shock. The decline in output is roughly reduced by half (peak decline is 0.27 percent in the baseline model while is 0.17 per cent in the model with credit policy intervention). This is because credit injection from the central bank increases banks' leverage. Risk premium rises by less with credit intervention. As a result, the demand for mortgage loan reduces by less and housing prices decline by less. 
Figure 8: Effects of a Negative Housing Demand Shock: Baseline vs Policy
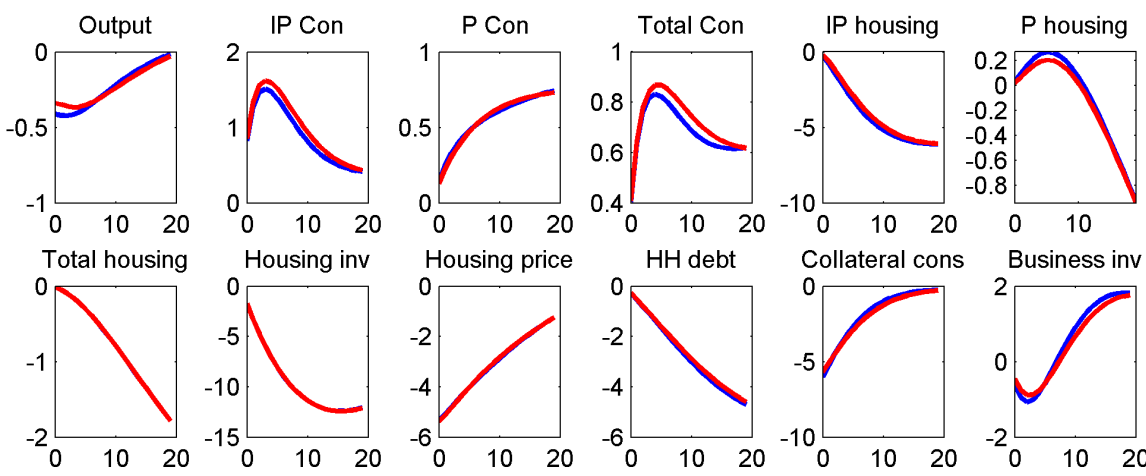

Collateral cons
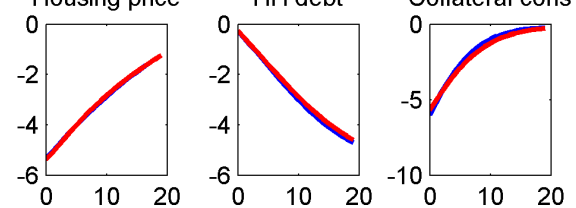

Business inv
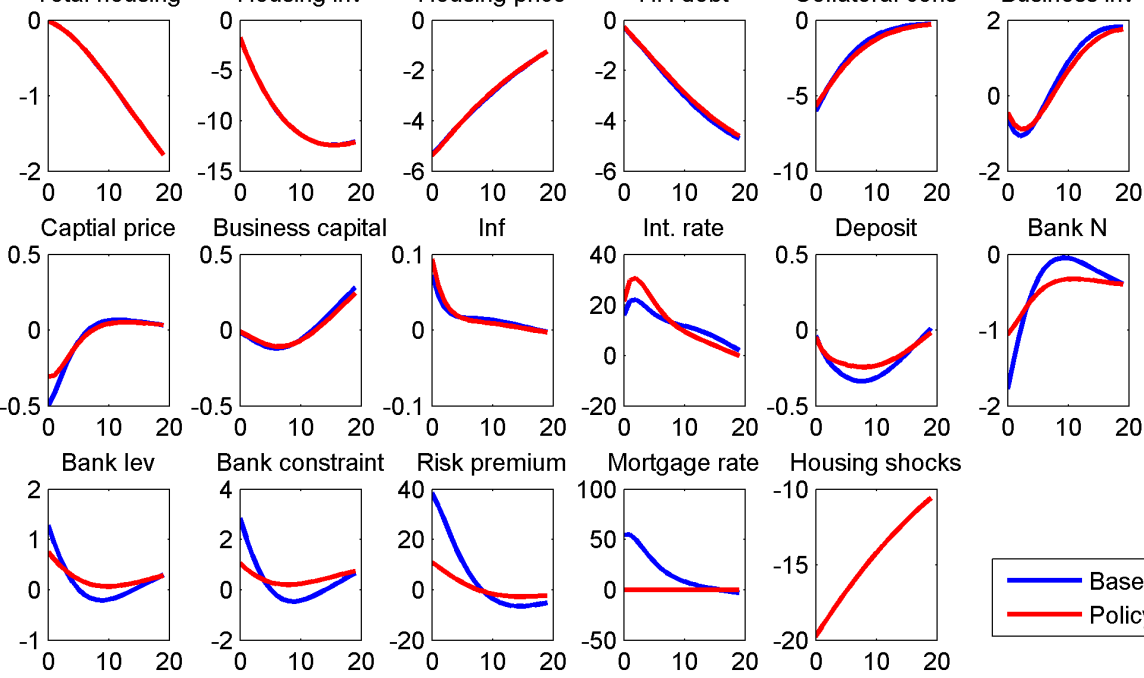

All the variables are in percentage deviations from their steady-state values except risk premium and mortgage rate which are in basis points. 
Figure 9: Effects of a Negative Banking Shock: Baseline vs Policy
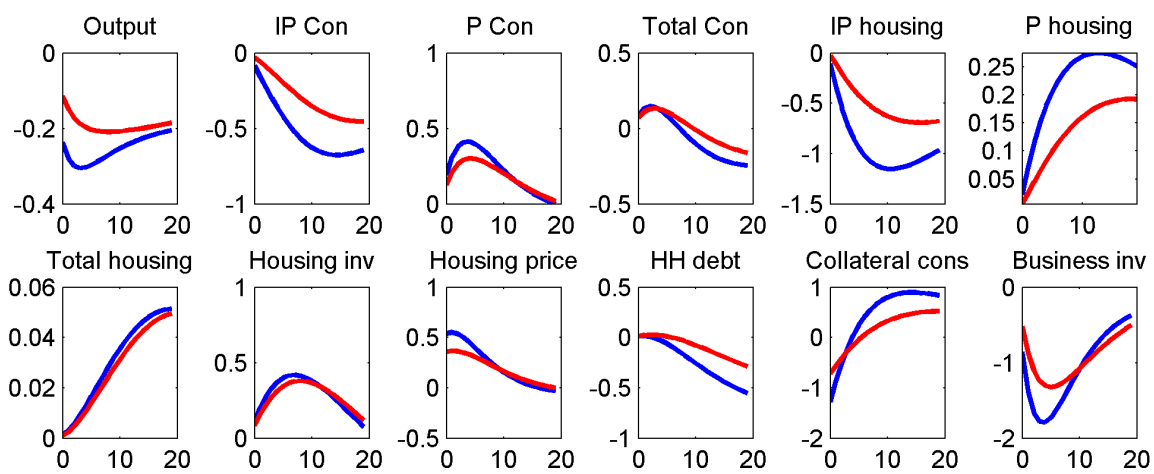

Collateral cons

Business inv
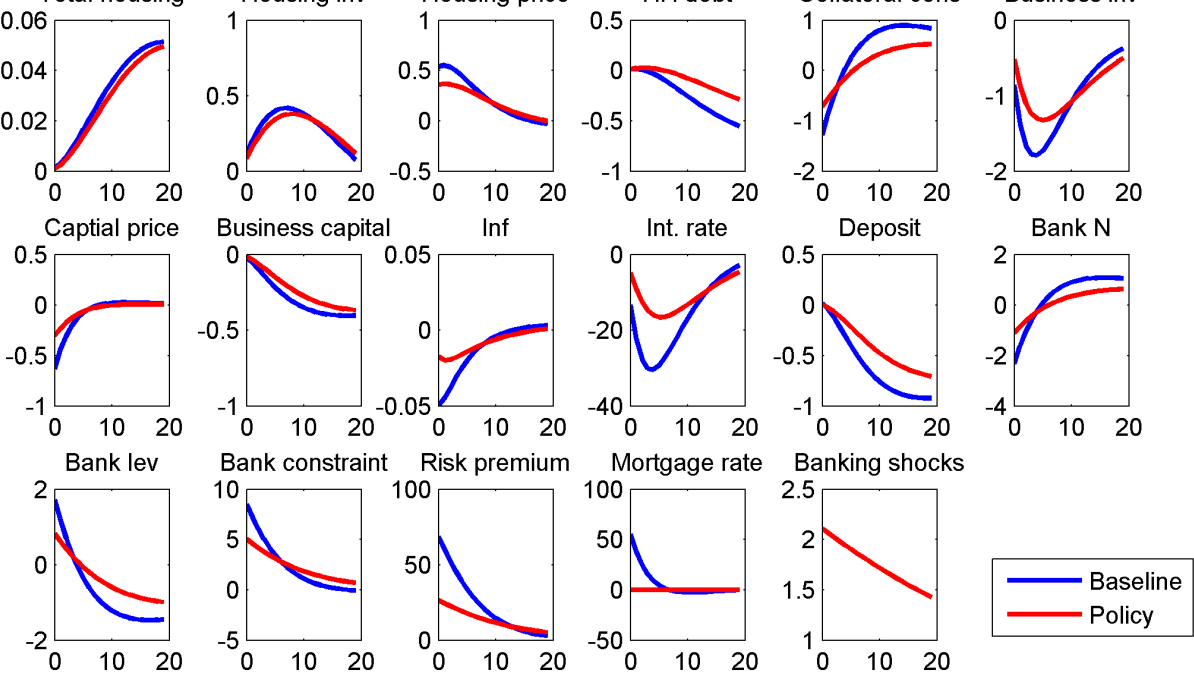

All variables are in percentage deviations from their steady-state values except risk premium and mortgage rate which are in basis points. 


\section{Conclusions}

The relationship between housing prices, household debt and monetary policy has been an important topic in the DSGE literature, and it became even more so since the Great Recession. In this paper I added a new dimension: a micro-founded banking sector. This allows the model to link housing prices, households debt and banks' balance sheet positions together. In the model, a shock that drives down housing prices also drives down the value of assets held by the banks, worsening the banks' balance sheet positions. As a results, risk premium rises, which sends the downturn even further. This mechanism captures what happened during the Great Recession in the U.S: the collapse in the housing market leads to a decline in banks' net worth as the banking sector holds significant amount of real estate assets and risk premium rises significantly.

This new dimension also makes the model more suitable for assessing the impact of the unconventional monetary policy, which injects the liquidity directly to the banking sector. I show that the unconventional monetary policy has mitigated the downturn in the U.S.

Although the model is quite successful in matching some key moments in the data, the volatility in consumption is obviously quite large compared to the data. A further investigation of the model specification regarding aggregate consumption is needed.

\section{Appendix A. System of Equations}

$$
\begin{gathered}
\varepsilon_{t}^{c} \frac{1}{c_{p, t}-b c_{p, t-1}}-\beta_{p} b \varepsilon_{t+1}^{c} \frac{1}{c_{p, t+1}-b c_{p, t}}-\lambda_{1 p, t}=0 \\
\lambda_{1, t}^{p}=E_{t} \beta_{p} R_{t} \frac{\lambda_{1, t+1}^{p}}{\pi_{t+1}} \\
\frac{\varepsilon_{t}^{c} \varepsilon_{t}^{h} \phi}{h_{p, t}}+\beta_{p} \lambda_{1, t+1}^{p} q_{t+1}\left(1-\delta_{h}\right)=q_{t} \lambda_{1, t}^{p} \\
\varphi n_{p, t}^{\eta}=\lambda_{1, t}^{p} w_{p, t} \\
\varepsilon_{t}^{c} \frac{1}{c_{i p, t}-b c_{i p, t-1}}-\beta_{p} b \varepsilon_{t+1}^{c} \frac{1}{c_{i p, t+1}-b c_{i p, t}}-\lambda_{1, t}^{i p}=0 \\
\lambda_{1, t}^{i p}=E_{t} \beta_{i p} R_{t}^{l} \frac{\lambda_{1, t+1}^{i p}}{\pi_{t+1}}+\lambda_{3, t}^{i p} R_{t}^{l}-E_{t} \beta_{i p} \lambda_{3, t+1}^{i p} R_{t+1}^{l} \rho^{l}, \\
\varepsilon_{t}^{c} \varepsilon_{t}^{h} \frac{\phi}{h_{i p, t}}+E_{t}\left\{\beta_{i p} \lambda_{1, t+1}^{i p} q_{t+1}\left(1-\delta^{h}\right)+\left(1-\rho^{l}\right) \lambda_{3, t}^{i p} \theta \varepsilon_{t}^{\theta} q_{t+1} \pi_{t+1}\left(1-\delta^{h}\right)\right\}=\lambda_{1, t}^{i p} q_{t} \\
\varphi n_{i p, t}^{\eta}=\lambda_{1, t}^{i p} w_{i p, t} \\
R_{t}^{l} l_{i p, t}=E_{t} \theta q_{t+1} \pi_{t+1} h_{i p, t}\left(1-\delta^{h}\right) \\
l_{t}=\rho_{t-1}^{l} l_{t-1}+\left(1-\rho^{l}\right) E_{t} \frac{\theta q_{t+1} \pi_{t+1} h_{i p, t}\left(1-\delta^{h}\right)}{R_{t}^{l}}
\end{gathered}
$$




$$
\begin{aligned}
& c_{i p, t}+q_{t} i_{i p, t}^{h}+R_{t-1}^{l} \frac{l_{t-1}}{\pi_{t}}=w_{i p, t} n_{i p, t}+l_{t} \\
& A_{t}=Q_{t}\left(k_{t}+l_{t}\right)=d_{t}+n_{t} \\
& \mu_{t}=\beta E_{t}\left[\left(R_{t+1}^{l}-R_{t+1}\right) \Omega_{t+1}\right] \\
& v_{d t}=\beta E_{t}\left[R_{t+1} \Omega_{t+1}\right] \\
& \Omega_{t+1}=1-\sigma+\sigma\left(v_{d t+1}+\phi_{t+1} \mu_{t+1}\right) \\
& n_{t}^{e}=\sigma\left[\left(R_{t}^{l}-R_{t}\right) \phi_{t-1}+R_{t}\right] n_{t-1} \\
& n_{t}^{n}=\omega A_{t-1} \\
& n=n_{t}^{n}+n_{t}^{e} \\
& \phi_{t}=\frac{A_{t}}{n_{t}}=\frac{v_{d t}}{\kappa-\mu_{t}} \\
& \lambda_{t}^{b}=\frac{\mu_{t}}{\theta-\mu_{t}} . \\
& y_{t}=A_{t} k_{t}^{\alpha}\left(\left(n_{p, t}\right)^{\gamma}\left(n_{i p, t}\right)^{1-\gamma}\right)^{1-\alpha} \\
& (1-\gamma) \alpha p_{t}^{w} \frac{y}{n_{p, t}}=w_{p, t} \\
& (1-\gamma)(1-\alpha) p_{t}^{w} \frac{y}{n_{i p, t}}=w_{i p, t} \\
& p_{t}^{w} \alpha \frac{Y_{t}}{k_{t}}=r_{t}^{k} \\
& Q_{t}=q_{t}^{k}, \\
& E_{t} R_{t+1}^{l}=\frac{E_{t}\left[r_{t+1}^{k}+q_{t+1}^{k}(1-\delta)\right]}{q_{t}^{k}} \\
& k_{t}=\left(1-\delta^{k}\right) k_{t-1}+\tau_{t}^{k} i_{t}^{k} \\
& \tau_{t}^{k} q_{t}^{k}=1+0.5 q_{t}^{k} \chi^{k}\left(\frac{i_{t}^{k}}{i_{t-1}^{k}}-1\right)^{2}+q_{t}^{k} \chi^{k}\left(\frac{i_{t}^{k}}{i_{t-1}^{k}}-1\right)\left(\frac{i_{t}^{k}}{i_{t-1}^{k}}\right)-\beta_{p} \Lambda_{t, t+1} q_{t+1} \chi^{k}\left(\frac{i_{t+1}^{k}}{i_{t}^{k}}-1\right)\left(\frac{i_{t+1}^{k}}{i_{t}^{k}}\right)^{2} \\
& h_{t}=\left(1-\delta^{h}\right) h_{t-1}+\tau_{t}^{h} i_{t}^{h} \\
& q_{t}=1+0.5 q_{t} \chi^{h}\left(\frac{i_{t}^{h}}{i_{t-1}^{h}}-1\right)^{2}+q_{t} \chi^{h}\left(\frac{i_{t}^{h}}{i_{t-1}^{h}}-1\right)\left(\frac{i_{t}^{h}}{i_{t-1}^{h}}\right)-\beta \Lambda_{t, t+1} q_{t+1} \chi^{h}\left(\frac{i_{t+1}^{h}}{i_{t}^{h}}-1\right)\left(\frac{i_{t+1}^{h}}{i_{t}^{h}}\right)^{2} \\
& p_{i, t}^{*}=\left(\frac{\varepsilon}{\varepsilon-1}\right) \frac{E_{t} \sum_{s=0}^{\infty} \nu^{s} \Delta_{s, t+s}^{p} m c_{t+1} y_{t+i}\left(\frac{1}{p_{t+i}}\right)^{-\varepsilon}}{E_{t} \sum_{s=0}^{\infty} \nu^{s} \Delta_{s, t+s}^{p} y_{t+i}\left(\frac{1}{p_{t+i}}\right)^{1-\varepsilon}} \\
& p_{t}=\left[\nu p_{t-1}^{1-\varepsilon}+(1-\nu)\left(p_{t}^{*}\right)^{1-\varepsilon}\right]^{\frac{1}{1-\varepsilon}}
\end{aligned}
$$




$$
\begin{gathered}
\frac{R_{t}}{R_{s s}}=\left(\frac{R_{t-1}}{R_{s s}}\right)^{\rho_{r}}\left(\left(\frac{\pi_{t}}{\pi_{s s}}\right)^{\rho_{\pi}}\left(\frac{y_{t}}{y_{s s}}\right)^{\rho_{y}}\right)^{1-\rho_{r}} e^{\epsilon_{t}^{m}} \\
G_{t}=t_{t} \\
c_{p, t}+c_{i p, t}+q_{t}\left(i_{p, t}^{h}+i_{i p, t}^{h}\right)+q_{t}^{k} i_{t}^{k}+0.5 \chi^{k}\left(\frac{i_{t}^{k}}{i_{t-1}^{k}}-1\right)^{2}+0.5 \chi^{h}\left(\frac{i_{t}^{h}}{i_{t-1}^{h}}-1\right)^{2}=y_{t} \\
h_{i p, t}+h_{p, t}=h_{t} \\
\ln \left(A_{t}\right)=\ln \left(A_{t-1}\right)+\zeta_{t}^{A} \\
\log g_{t}=\left(1-\rho^{g}\right) \log g_{s s}+\rho^{g} \log g_{t-1}+\zeta_{t}^{g}, \zeta_{t}^{g} \sim i . i . d . N\left(0, \sigma_{\epsilon^{g}}^{2}\right) \\
\log \tau_{t}^{k}=\rho_{k} \log \tau_{t-1}^{k}+\zeta_{t}^{\tau^{k}}, \zeta_{t}^{\tau^{k}} \sim i . i . d . N\left(0, \sigma_{\zeta^{\tau k}}^{2}\right) . \\
\log \varepsilon_{t}^{c}=\rho^{c} \log \varepsilon_{t-1}^{c}+\zeta_{t}^{c} \\
\log \varepsilon_{t}^{h}=\rho^{h} \log \varepsilon_{t-1}^{h}+\zeta_{t}^{h} \\
\log \varepsilon_{t}^{\kappa}=\rho^{\kappa} \log \varepsilon_{t-1}^{\kappa}+\zeta_{t}^{\kappa} . \\
\log \varepsilon_{t}^{\theta}=\rho^{\theta} \log \varepsilon_{t-1}^{\theta}+\zeta_{t}^{\theta} .
\end{gathered}
$$

\section{Appendix B: Steady State}

$$
\begin{gathered}
\pi_{s s}=1 \\
R^{d}=\frac{1}{\beta_{p}} \\
R^{l}=R^{d}+s \\
\lambda_{3}=\lambda_{1 p} \frac{\left(\frac{1}{R^{l}}-\frac{\beta_{i p}}{\pi}\right)}{\left(1-\beta_{i p} \rho^{l}\right)} \\
\lambda_{1 p}=\frac{\left(1-\beta_{p} b\right)}{(1-b) c_{p}} \\
q=\zeta_{3} \frac{c_{p}}{h_{p}}
\end{gathered}
$$

where

$$
\begin{gathered}
\zeta_{3}=\frac{\phi(1-b)}{\left(1-\beta_{p}\left(1-\delta_{h}\right)\right)\left(1-\beta_{p} b\right)} \\
q=\zeta_{4} \frac{c_{i p}}{h_{i p}}
\end{gathered}
$$

where

$$
\zeta_{4}=\frac{\phi(1-b)}{\left[1-\beta_{i p}\left(1-\delta_{h}\right)-\frac{1-\rho^{l}}{1-\beta \rho^{l}}\left(\frac{1}{R^{l}}-\frac{\beta_{i p}}{\pi}\right) \pi \theta\left(1-\delta_{h}\right)\right]\left(1-\beta_{i p} b\right)}
$$




$$
\begin{gathered}
l=\frac{\theta q \pi h_{i p}\left(1-\delta_{h}\right)}{R^{l}} \\
c_{i p}=\frac{\frac{(1-\alpha)(1-\gamma)}{X}}{1+\left(\frac{1}{\pi}-\frac{1}{R^{l}}\right) \theta \pi\left(1-\delta_{h}\right) \zeta_{4}+\delta_{h} \zeta_{4}} y=\zeta_{6} y
\end{gathered}
$$

where

$$
\begin{aligned}
& \zeta_{6}=\frac{\frac{(1-\alpha)(1-\gamma)}{X}}{1+\left(\frac{1}{\pi}-\frac{1}{R^{l}}\right) \theta \pi\left(1-\delta_{h}\right) \zeta_{4}+\delta_{h} \zeta_{4}} \\
& l=\frac{\theta \pi\left(1-\delta_{h}\right)}{R^{l}} \zeta_{4} c_{i p} \\
& q=Q=q^{k}=1 \\
& k=\frac{\gamma}{X\left(R^{l}-(1-\delta)\right)} \\
& i^{k}=\delta k \\
& A=k+l \\
& \Omega=\frac{1-\sigma}{1-\sigma \beta^{p} R-\sigma \phi \beta^{p} \tau} \\
& \mu=\beta^{p} \tau \Omega=\frac{\beta^{p} \tau(1-\sigma)}{1-\sigma \beta^{p} R-\sigma \phi \beta^{p} \tau} \\
& v_{d}=\frac{\beta^{p} R(1-\sigma)}{1-\sigma \beta^{p} R-\sigma \phi \beta^{p} \tau} . \\
& \omega=\frac{(1-\sigma(\tau \phi+R))}{\phi} \\
& n^{n}=\omega A \\
& n=\frac{n^{n}}{1-\omega \phi} \\
& n^{e}=n-n^{n} \\
& d=A-n \\
& g=g_{y} y \\
& g=t \\
& c_{p}=\frac{\alpha(1-\gamma)}{X} y+\left(1-\frac{1}{X}\right) y-\left(1-\frac{R}{\pi}\right) d-\delta^{h} h^{p}+(1-\sigma) n-n^{n}-t \\
& h_{p}=c_{p} \zeta_{3} \\
& h_{i p}=c_{i p} \zeta_{4}
\end{aligned}
$$




$$
\begin{gathered}
h=h_{p}+h_{i p} \\
i^{h}=\delta^{h} h \\
\lambda_{1 p}=\frac{\left(1-\beta_{p} b\right)}{(1-b) c_{p}} \\
\lambda_{1 i p}=\frac{\left(1-\beta_{p} b\right)}{(1-b) c_{i p}} \\
n_{i p}=\left[\frac{(1-\gamma)(1-\alpha) y}{(\varphi X) / \lambda_{1 i p}}\right]^{\frac{1}{1+\eta}} \\
n_{p}=\left[\frac{(1-\gamma) \alpha y}{(\varphi X) / \lambda_{1 p}}\right]^{\frac{1}{1+\eta}} \\
w_{i p}=\frac{\varphi n_{i p}^{\eta}}{\lambda_{1 i p}} \\
w_{p}=\frac{\varphi n_{i p}^{\eta}}{\lambda_{1 p}}
\end{gathered}
$$

\section{Appendix C. Data Construction}

The model is estimated with U.S. quarterly data from 1991Q1 to 2014Q1. I use the following time series as observables. The data is download from FRED - Federal Reserve Economic Data from the St. Louis Fed.

1.Output

Model variable: $y_{t}$.

Data: original series: GDPC1, normalized by civilian population and GDP deflator. The series is $\log$ trans-formed, and detrended with a quadratic trend.

2. Consumption:

Model: $c_{t}$

Data: includes nondurable consumption goods and services. Original series: PCND+PCESVGDPC1, normalized by civilian population and GDP deflator. The series is log trans-formed, and detrended with a quadratic trend

3.Business investment:

Model variable: $i_{t}^{k}$

Data: includes durable consumption goods and private investment. Original series: PCDG+PNFI. Normalized by civilian population and GDP deflator. The series is log transformed, and detrended with a quadratic trend.

4. Housing investment

Model variable: $i_{t}^{h}$

Data: includes durable consumption goods and private investment. Original series: PRFI. Normalized by civilian population and GDP deflator. The series is log transformed, and detrended with 
a quadratic trend.

5. Mortgage debt

Model variable: $l_{t}$

Data: Montage debt outstanding. Original series: MDOAH. Normalized by civilian population and GDP deflator. The series is log transformed, and detrended with a quadratic trend.

6. House prices:

Model variable: $q_{t}$

Data: S\&P/Case-Shiller Home Price Indices. Original series: USCSCOMHPISA. The series is $\log$ transformed, and detrended with a quadratic trend.

7. Risk premium:

Model variable: $s_{t}$

Data: Average of risk premium for business loans and residential mortgage loans. Business loan risk premium is constructed using BAA10YM, the difference between BAA and 10 year government bond yields. Residential loans risk premium is constructed using 30 year fixed rate mortgage loan minus the average of 10 year government debt yield and 5 year government debt yield. That is: MORTGAGE30US-1/2*(GS5+GS10).

8. Nominal interest rate

Model variable: $R_{t}$

Data: Effective Federal Funds Rate, FEDFUNDS

9. Inflation

Model variable: $\pi_{t}$

Data: Quarterly difference of the GDP deflator GDPDEF 


\section{References}

Bernanke, B. S., Gertler, M., and Gilchrist, S. (1999). The financial accelerator in a quantitative business cycle framework. Handbook of macroeconomics, 1:1341-1393.

Calvo, G. A. (1983). Staggered prices in a utility-maximizing framework. Journal of monetary Economics, 12(3):383-398.

Christiano, L. J., Eichenbaum, M., and Evans, C. L. (2005). Nominal rigidities and the dynamic effects of a shock to monetary policy. Journal of political Economy, 113(1):1-45.

Duca, J. V., Muellbauer, J., and Murphy, A. (2011). House prices and credit constraints: Making sense of the us experience. The Economic Journal, 121(552):533-551.

Gertler, M. and Karadi, P. (2011). A model of unconventional monetary policy. Journal of monetary Economics, 58(1):17-34.

Gertler, M. and Kiyotaki, N. (2015). Banking, liquidity and bank runs in an infinite-horizon economy. American Economic Review, 105(7):2011-43.

Hall, R. E. (2011). The long slump. Technical report, National Bureau of Economic Research.

Iacoviello, M. (2005). House prices, borrowing constraints, and monetary policy in the business cycle. American economic review, pages 739-764.

Iacoviello, M. (2015). Financial business cycles. Review of Economic Dynamics, 70:22-38.

Justiniano, A., Primiceri, G. E., and Tambalotti, A. (2015). Household leveraging and deleveraging. Review of Economic Dynamics, 18(1):3-20.

Kiyotaki, N. and Moore, J. (1997). Credit cycles. Journal of Political Economy, 105(2):211-248.

Neri, S. and Iacoviello, M. (2010). Housing market spillovers: Evidence from an estimated dsge model. American Economic Journal: Macroeconomics, 2(2):125-164.

Smets, F. and Wouters, R. (2007). Shocks and frictions in us business cycles: A bayesian dsge approach. American economic review, 97(3):586-606. 